\title{
Multiple Mechanisms of Bursting in a Conditional Bursting Neuron
}

\author{
Ronald M. Harris-Warrick and Robert E. Flamma \\ Section of Neurobiology and Behavior, Seeley G. Mudd Hall, Cornell University, Ithaca, New York 14853
}

\begin{abstract}
The anterior burster $(A B)$ neuron in the stomatogastric ganglion of the spiny lobster, Panulirus interruptus, is a conditional burster in the pyloric motor circuit. Bath application of the monoamines dopamine, serotonin, and octopamine induces rhythmic bursting pacemaker potentials in a silent, synaptically isolated $A B$ cell. However, each amine produces a unique and characteristic burst shape, resulting from different ionic dependences of the burst mechanisms. Bursting induced by serotonin or octopamine is critically dependent upon sodium entry through tetrodotoxin-sensitive channels; dopamine-induced bursting is not TTX-sensitive. Dopamineinduced bursting is abolished when extracellular calcium is reduced to $25 \%$ of normal; serotonin- and octopamine-induced bursts continue in this saline, although they are abolished in salines with calcium reduced to $10 \%$ or less of normal. Quantitative differences between the amines are also seen in the tetraethylammonium (TEA) sensitivity of the burst amplitude and in the dependence of the interburst hyperpolarization on extracellular potassium. These experiments demonstrate that there are both quantitative and qualitative differences in the ionic currents underlying every phase of the bursts induced by the 3 amines. Thus, a single neuron can burst via more than one ionic mechanism.
\end{abstract}

Endogenously bursting neurons have been detected in a number of different species (Berridge and Rapp, 1979; Rapp, 1979; Pinsker and Ayers, 1983; Connor, 1985) and play important roles in the generation and coordination of simple rhythmic motor programs (Getting, 1987). A major focus of recent research has been on the ionic mechanisms involved in the generation and maintenance of the slow membrane potential oscillations that underlie endogenous bursting. Bursting neurons fall into 2 major classes. Constitutive bursters continue to fire rhythmic bursts of impulses when completely isolated from all synaptic input. The ionic conductances in constitutive molluscan bursters have been studied intensively, using voltage-clamp methods (Gorman et al., 1980, 1982; Smith, 1980; Adams, 1985; Adams and Benson, 1985; Adams and Levitan, 1985; Kramer and Zucker, $1985 \mathrm{a}, \mathrm{b})$. Models of molluscan bursting are complex, involving

\footnotetext{
Received Aug. 8, 1986; revised Dec. 30, 1986; accepted Jan. 8, 1987.

Supported by NIH Grant NS17323 and Hatch Act Grant NYC-191410. R.E.F. was supported by NIH Predoctoral Training Grant 5 T32 GM07469. We thank Drs. I. Levitan, R. Zucker, R. Kramer, B. Johnson, and P. Katz for careful critiques of an earlier version of the manuscript, D. Fickbohm for technical assistance, and $\mathrm{S}$. Singer for assistance in preparation of the figures.

Correspondence should be addressed to Ronald Harris-Warrick, Section of Neurobiology and Behavior, Seeley G. Mudd Hall, Cornell University, Ithaca, NY 14853.

a Present address: Department of Pharmacology, Yale University School of Medicine, New Haven, CT 06511.

Copyright (C) 1987 Society for Neuroscience $0270-6474 / 87 / 072113-16 \$ 02.00 / 0$
}

many conductances active at appropriate times during the burst. The current evidence suggests that the ionic mechanisms for bursting vary between different cells.

Conditional bursters are a second class of endogenously bursting neurons. In these cells, the ionic mechanisms that generate rhythmic activity must be activated by unpatterned modulatory input; when isolated, these cells lose the ability to burst. A number of studies have analyzed the ionic mechanisms of burst induction and maintenance in conditional bursting cells (Tazaki and Cooke, 1979, 1983; Gola and Selverston, 1981; Benson and Cooke, 1984; Berlind, 1985). Most studies of the induction of conditional bursting have focused on a single major conductance change in the affected cell (Barker and Smith, 1976; Benson and Cooke, 1984; Nagy et al., 1984, 1985; McCormick and Prince, 1986). However, given the extraordinary complexity of the currents underlying bursting, it is likely that several conductances are simultaneously affected. A basic assumption in many of these studies has been that there is only one mechanism for generating bursting in a particular cell.

The anterior burster $(\mathrm{AB})$ neuron in the stomatogastric ganglion of the spiny lobster, Panulirus interruptus, is a conditional burster. This cell is the primary pacemaker neuron for rhythmic activity in the central pattern generator (CPG) circuit for the pyloric rhythm in the lobster stomach (Miller and Selverston, 1982a, 1985). When modulatory inputs from other ganglia are intact or are tonically stimulated, the AB neuron generates largeamplitude membrane potential oscillations, called bursting pacemaker potentials, or BPPs (Selverston et al. 1976; Miller and Selverston, 1982b). Gola and Selverston (1981) performed the first study of the mechanisms of bursting in $A B$ and pyloric dilator (PD) neurons under these conditions. In their model, a BPP is initiated and maintained by a combination of prolonged sodium and calcium currents and terminated by a calciumactivated potassium conductance. When modulatory inputs from other ganglia are removed, the $\mathrm{AB}$ ncuron loses its bursting capability and falls silent (Miller and Selverston, 1985; Moulins and Nagy, 1985). Several neuromodulators can restore endogenous bursting in a quiescent $A B$ neuron; these include the amines dopamine (DA), serotonin (5-HT), and octopamine (OCT) (Raper, 1979; Anderson and Barker, 1981; Beltz et al., 1984; Marder and Eisen, 1984b; Flamm and Harris-Warrick, 1986a, b), muscarinic agonists (Marder and Eisen, 1984a; Nagy et al., 1984, 1985; Moulins and Nagy, 1985), and the peptides proctolin and FMRF amide (Hooper and Marder, 1984). Nagy et al. $(1984,1985)$ proposed that muscarinic agonists can activate bursting in $\mathrm{AB}$ and $\mathrm{PD}$ cells by reducing a tonic TEAsensitive potassium conductance, thus uncovering a prolonged inward calcium current. In these studies, the cell was not completely isolated from synaptic input, and the cellular origin of the BPPs was not clear. 
We have comparcd the induction of bursting by DA, 5-HT, and $\mathrm{OCT}$ in $\mathrm{AB}$ neurons that have been isolated from all detectable synaptic input (Flamm and Harris-Warrick, 1986b). We and others (Gola and Selverston, 1981) have attempted to voltage-clamp the currents generated by a rhythmically bursting $\mathrm{AB}$ neuron, but so far without success. Like many crustacean neurons, the somata of the cells in the stomatogastric ganglion (STG) are electrically unexcitable (Selverston et al., 1976), and voltage-clamp measurements from isolated somata have thus far demonstrated only outward currents (Hartline et al., 1985). The BPP-generating currents arise in the neuropil at a distance too great for adequate clamp from the soma. As a consequence, we have used ion substitutions and pharmacological blockade to study the ionic mechanisms of bursting in the AB cell. Our results show that this single cell can be induced to burst by more than one ionic mechanism. The 3 amines generate bursting by means of different combinations of ionic currents, which, in turn, generate BPPs of different amplitude and frequency.

\section{Materials and Methods}

Pacific spiny lobsters (Panulirus interruptus) were purchased from Marinus (Westchester, CA) and kept in marine aquaria (Instant Ocean, Aquarium Systems) at $16-17^{\circ} \mathrm{C}$ until use. The stomatogastric nervous system was removed from the animal, as described by Mulloney and Selverston (1974), and superfused at $5 \mathrm{ml} / \mathrm{min}$ with cold $\left(14-16^{\circ} \mathrm{C}\right)$ oxygenated saline (composition in mM: $\mathrm{NaCl}, 479 ; \mathrm{KCl}, 12.8 ; \mathrm{CaCl}_{2}$, 13.7; $\mathrm{Na}_{2} \mathrm{SO}_{4}, 3.9 ; \mathrm{MgSO}_{4}, 10.0$; glucose, 2.0; Tris base, 11.1; maleic acid, $5.1 ; \mathrm{pH} 7.35$ ).

Synaptic isolation of the $A B$ neuron. The $\mathrm{AB}$ neuron was identified by the following criteria: (1) In actively cycling preparations, it fired synchronously with the PD neurons, whose action potentials were monitored with extracellular recordings from the PD nerve. (2) Its intracellular membrane potential BPP shape was distinctive, with a large BPP (usually $10-20 \mathrm{mV}$ ) and small action potentials (usually $2-5 \mathrm{mV}$ ). (3) Its cell body was small $(40-50 \mu \mathrm{m})$ compared to the larger PD cells (100-150 $\mu \mathrm{m})$.

Two steps were used to eliminate all detectable synaptic input to the AB cell while retaining it in situ in the STG (Flamm and Harris-Warrick, 1986b). First, synaptic inputs from the commissural and esophageal ganglia entering the STG via the stomatogastric nerve were eliminated by a sucrose block. A ring of Vaseline at least $1 \mathrm{~cm}$ in diameter was placed on the nerve, and the saline in the ring was replaced by isotonic sucrose with $10^{-6} \mathrm{M}$ TTX. In many experiments, $10^{-6} \mathrm{M}$ TTX was also added to the commissural and esophageal ganglia, which were separated from the STG by a Vaseline barrier. Second, synaptic inputs from neurons within the STG were eliminated by photoinactivation (Miller and Selverston, $1979,1982 \mathrm{~b}$ ). The only neurons in the STG that synapse on the $\mathrm{AB}$ are the ventral dilator (VD) and the $2 \mathrm{PD}$ cells (Eisen and Marder, 1982; Miller and Selverston, 1982b). These cells were readily identified by a $1: 1$ correlation between their action potentials, recorded intracellularly and extracellularly on the proper motor nerve root, and by their distinctive BPP shapes. They were impaled with microelectrodes filled with 5,6-carboxyfluorescein (Kodak; $3 \%$ in distilled water, $\mathrm{pH}$ adjusted to 7.0 and filtered; electrodes backfilled with $0.2 \mathrm{M} \mathrm{LiCl}$; resistance, 10-20 M $\Omega$ ). Carboxyfluorescein was iontophoresed into the cells with 6-8 nA hyperpolarizing current pulses, $600 \mathrm{msec}$ in duration, at $1 \mathrm{~Hz}$ for $10-15 \mathrm{~min}$, until the cell body was bright yellow under normal illumination. After $10 \mathrm{~min}$, the cells were exposed for $10 \mathrm{~min}$ to bright blue light (wavelength, $390-490 \mathrm{~nm} ; 50 \mathrm{~W}$ mercury lamp) via an epifluorescence attachment to the dissecting microscope (Wild M5A). A cell was determined to be killed by 3 criteria (Eisen and Marder, 1982; Miller and Selverston, 1982b): (1) its action potentials in nerve roots were abolished; (2) its membrane potential was 0 ; (3) synaptic potentials in postsynaptic cells were abolished. Although the $A B$ is electrically coupled to all 3 of the photoinactivated cells, it is not dyecoupled to them (Miller and Selverston, 1982b; and unpublished observations). After photoinactivation, the AB had a transient decrease in membrane resistance, which recovered in about $1 \mathrm{hr}$. We always waited at least $2 \mathrm{hr}$ after photoinactivation before beginning the experiment.

After these treatments, no synaptic input was detectable in the $A B$ neuron for the remainder of the experiment. Although potential sources of input remain (discussed in Flamm and Harris-Warrick, 1986b), they were never in fact observed. The $A B$ is referred to as a synaptically isolated neuron after these treatments.

Recording techniques. The synaptically isolated $\mathrm{AB}$ neuron was impaled with a beveled microelectrode (filled with $4 \mathrm{M}$ potassium acetate; resistance, 20-25 M $\Omega$ ). For many experiments, the amplification was conventional. For current injection, a switched, single-electrode instrument was used (Almost Perfect Electronics, Basel), which obviated problems of bridge balance. Typical recordings were stable for 6-12 hr. Data were stored on magnetic tape and analyzed by hand or using programs written for a MINC-11 microcomputer (Digital Equipment Corp.). The burst peak was measured at the base of the most depolarized action potential during a burst. Thus, the amplitudes of the action potentials are not included in this value. The interburst hyperpolarization, or burst trough, was measured at the most hyperpolarized point between 2 bursts.

The following drugs were dissolved in cold lobster saline $\left(15-17^{\circ} \mathrm{C}\right)$ just prior to use and superfused over the preparation for 10-45 min at $5 \mathrm{ml} / \mathrm{min}$ : dopamine $\mathrm{HCl}$, octopamine $\mathrm{HCl}$, serotonin creatinine sulfate, and tetrodotoxin (Sigma Chemical Co., St. Louis, MO); tetraethylammonium chloride (TEA) (Aldrich Chemical Co.). Amines were added in random order; the order of presentation did not affect the results. For experiments with altered extracellular sodium, a $0 \mathrm{Na}^{+}$saline in which all the $\mathrm{NaCl}$ was replaced with either $580 \mathrm{~mm}$ Tris- $\mathrm{HCl}(\mathrm{pH} 7.4)$ or $674 \mathrm{~mm}$ sucrose was prepared (Gola and Selverston, 1981). This was mixed in appropriate proportions with the normal saline to prepare reduced-sodium salines. Similar experiments, varying extracellular calcium concentrations, were performed by mixing normal saline with a saline in which all $\mathrm{CaCl}_{2}$ was replaced with $\mathrm{MgCl}_{2}$. In some experiments, $100 \mu \mathrm{M} \mathrm{CdCl}_{2}$ or $10 \mathrm{mM} \mathrm{CoCl}_{2}$ was added directly to the normal saline. For experiments with altered extracellular potassium, salines with no $\mathrm{KCl}$ (replaced by $\mathrm{NaCl}$ ) or with 4 times the normal $\mathrm{K}$ (balanced by removal of $\mathrm{NaCl}$ ) were mixed in appropriate proportions. In all experiments, the preparation was washed with normal saline for at least 45 min between drug applications.

\section{Results}

\section{Bursting pacemaker potentials of different amplitudes and} shapes induced by different amines

In all of our experiments, the $\mathrm{AB}$ neuron was isolated from all detectable synaptic input by photoinactivation and sucrose block, as described in Materials and Methods. Under these conditions, the $\mathrm{AB}$ cell usually became inactive and displayed a flat resting potential (Fig. 1, lop). However, in approximately $20 \%$ of our preparations, the $\mathrm{AB}$ continued to show weak bursting activity (see, for example, the control for 5-HT of Fig. 2). We obtained the same results in both states, except where otherwise noted.

Bath application of DA $\left(10^{-4} \mathrm{M}\right)$, OCT $\left(10^{-4} \mathrm{M}\right)$, or 5-HT $\left(10^{-5}\right.$ M) initiated rhythmic BPPs in all preparations. However, the BPP shape was different with each amine (Fig. 1; Flamm and Harris-Warrick, 1986b). The most obvious difference was in the BPP amplitude. Absolute amplitudes varied considerably from experiment to experiment, but relative differences in amplitude of amine-induced BPPs did not. In 8 experiments in which each of the 3 amines was added sequentially to the same cell in normal saline, the BPP amplitude was always largest for DA and smallest for OCT (Table 1). The larger, DA-induced bursts also elicited more action potentials per burst than did the smaller, OCTinduced bursts (see, for example, Fig. 1 and Fig. 7). In addition, the amplitudes of the action potentials were different, with the smallest-amplitude spikes seen during DA and the largest during OCT (Table 1).

A second difference in BPP shape was the absolute value of the interburst hyperpolarization, or burst trough. In 6 of 8 preparations with no spontaneous bursting activity, the interburst trough of the DA-induced BPP was hyperpolarized from the pre-amine resting potential, shown by the line to the right of the traces in Figure 1 (see also Table 1). Similar results were 
c

DA

(1)
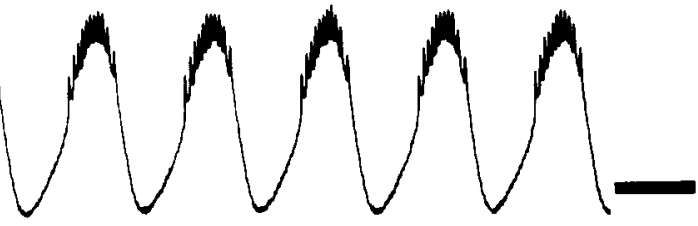

\section{5-HT}
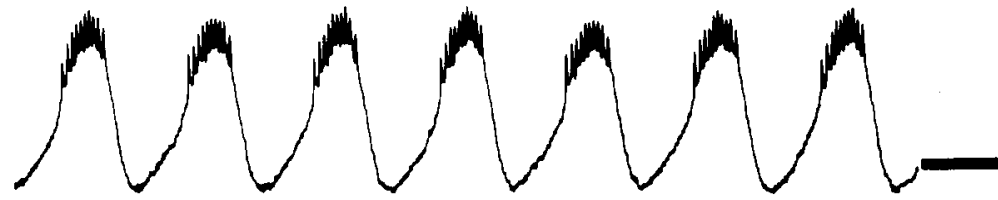

OCT
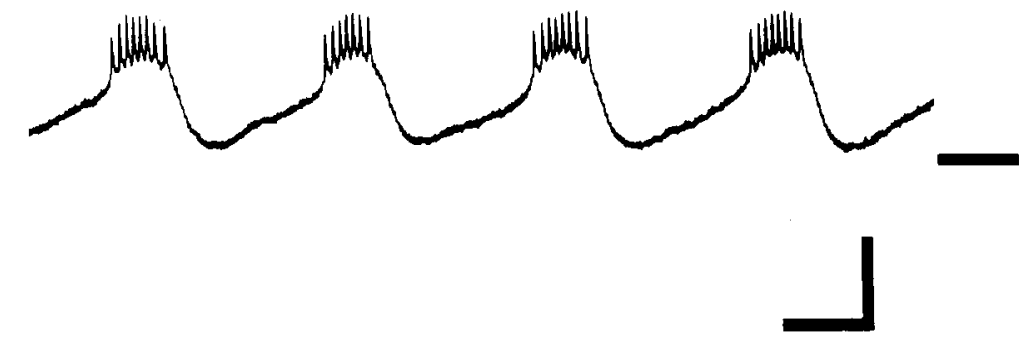

seen in 7 of 8 experiments with 5 -HT. In contrast, in 7 of 8 experiments with OCT, the burst trough was depolarized from the resting potential, so that the entire BPP was entirely depolarized from the previous resting potential.

A final difference between the amines was the burst frequency, which was highest for DA in all 8 experiments and lowest for OCT in 5 out of 8 experiments in which all 3 amines were applied in normal saline. Again, the absolute burst periods varied between experiments, but the relative frequencies were fairly constant between amines. When normalized to the burst period

for DA in each experiment, the burst period for 5-HT was $47 \%$ longer, while that for OCT was $119 \%$ longer (Table 1).

Thus, the amplitude, shape, and frequency of the BPPs induced by the 3 amines were all different. These results were obtained with saturating concentrations of each amine, as determined by previous dose-response studies (Flamm and Harris-Warrick, 1986a). Increases in OCT or 5-HT concentrations did not further alter the $\mathrm{AB}$ bursting response or make the bursts more similar to each other or to those induced by DA. This suggests that the ionic mechanisms generating the BPP are at

Table 1. Comparison of effects of amines on BPPs in isolated AB cells

\begin{tabular}{lccc} 
Measurement & DA & 5-HT & OCT \\
\hline BPP amplitude (mV) & $14.2 \pm 1.4$ & $12.2 \pm 1.1$ & $7.4 \pm 1.1^{a, b}$ \\
& $(100 \%)$ & $(86 \%)$ & $(52 \%)$ \\
Spike amplitude (mV) & $2.8 \pm 0.7$ & $3.6 \pm 0.7$ & $4.6 \pm 1.2^{a, b}$ \\
& $(100 \%)$ & $(129 \%)$ & $(164 \%)$ \\
Burst period (sec) & $1.03 \pm 0.13$ & $1.51 \pm 0.2^{a}$ & $2.26 \pm 0.66^{a}$ \\
& $(100 \%)$ & $(147 \%)$ & $(219 \%)$ \\
Interburst hyperpolarization $(\mathrm{mV})^{c}$ & $-1.6 \pm 0.7$ & $-1.7 \pm 0.6$ & $+1.4 \pm 0.7^{a, b}$
\end{tabular}

For dopamine, $n=12$; for serotonin, $n=9 ;$ for octopamine, $n=8$. Data are taken from experiments in which all 3 amines were sequentially added to a single cell; occasionally DA or 5-HT was added twice in the same experiment. All measurements are means \pm SE. Percentages shown in parentheses are comparisons with values obtained with DA.

a Statistically different from DA $(p<0.05$; Student's $t$ test $)$.

${ }^{b}$ Statistically different from 5-HT ( $p<0.05$; Student's $t$ test).

$c$ Values measured relative to pre-amine resting potential. 


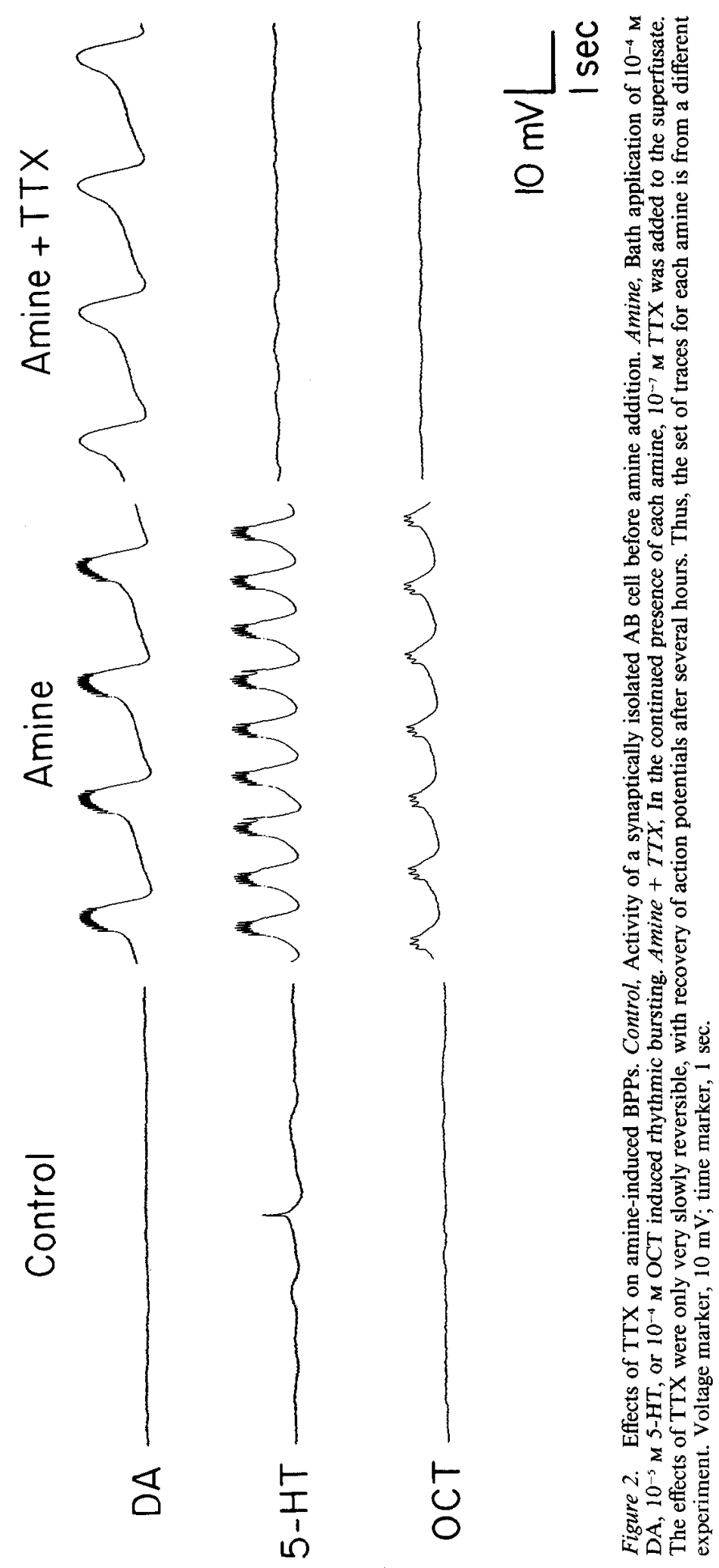




\section{$10^{-5}$ M 5-HT, $10^{-7} \mathrm{M}$ TTX}
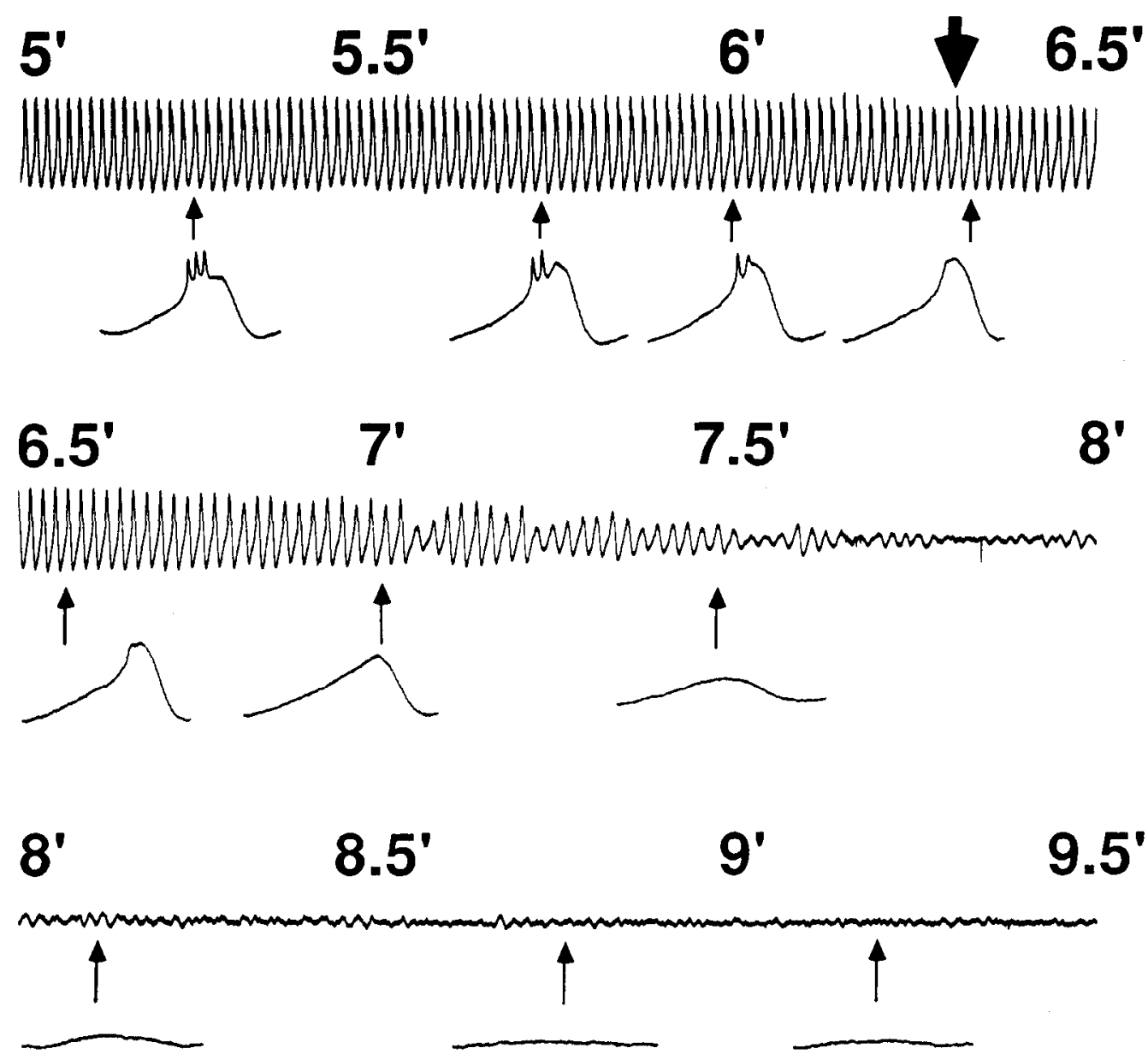

Figure 3. Time course of the TTX-induced failure of 5-HT-induced BPPs. Bursting was induced in a synaptically isolated AB cell by addition of $10^{-5} \mathrm{M}$ 5-HT. Once stable bursting was established, $10^{-7} \mathrm{M}$ TTX was added in the continued presence of 5-HT. The slow-speed traces show a continuous record of membrane potential between 5 and 9.5 min after TTX was added. Sample traces at higher sweep speed show BPPs at the times indicated by the arrows under the slow-speed recording. At about 6.3 min (large downward arrow), the last BPP with a detectable all-ornone action potential occurred. From 6.5 to about $7 \mathrm{~min}$, the cell continued to generate regular rhythmic BPPs with no action potentials and a slowly declining peak amplitude. The BPPs became irregular and declined in amplitude until they were no longer detectable. Voltage marker, 10 $\mathrm{mV}$; time marker, $1 \mathrm{sec}$ (fast sweep) or $12.5 \mathrm{sec}$ (slow sweep).

least quantitatively, if not qualitatively, different for DA, 5-HT, and OCT. The experiments described below demonstrate that this is the case.

\section{Role of sodium}

The role of sodium currents in amine-induced BPPs was investigated in 2 ways. First, TTX was used to evaluate the role of voltage-sensitive sodium channels (Fig. 2). In one series of experiments, rhythmic bursting was generated by the addition of one of the 3 amines to a quiescent, nonbursting $A B$ cell, then $10^{-7} \mathrm{M}$ TTX was added in the continued presence of the amine. Action potentials were abolished within several minutes of TTX entry into the bath. BPPs induced by DA continued with little change in amplitude or frequency after all action potentials became undetectable (Fig. 2). This rhythmic oscillation was stable as long as DA was applied with TTX (at least $45 \mathrm{~min}$ ). By contrast, in cells with no baseline bursting activity, BPPs generated by $5-\mathrm{HT}$ or OCT rapidly disappeared following the abolition of action potentials by TTX (Fig. 2). This elimination of BPP capability did not coincide exactly with the abolition of action potentials, however (Fig. 3): bursting with decreasing amplitude oscillations continued for periods varying from 15 sec to several minutes after action potential failure. This probably reflected the time required for TTX to diffuse from the 


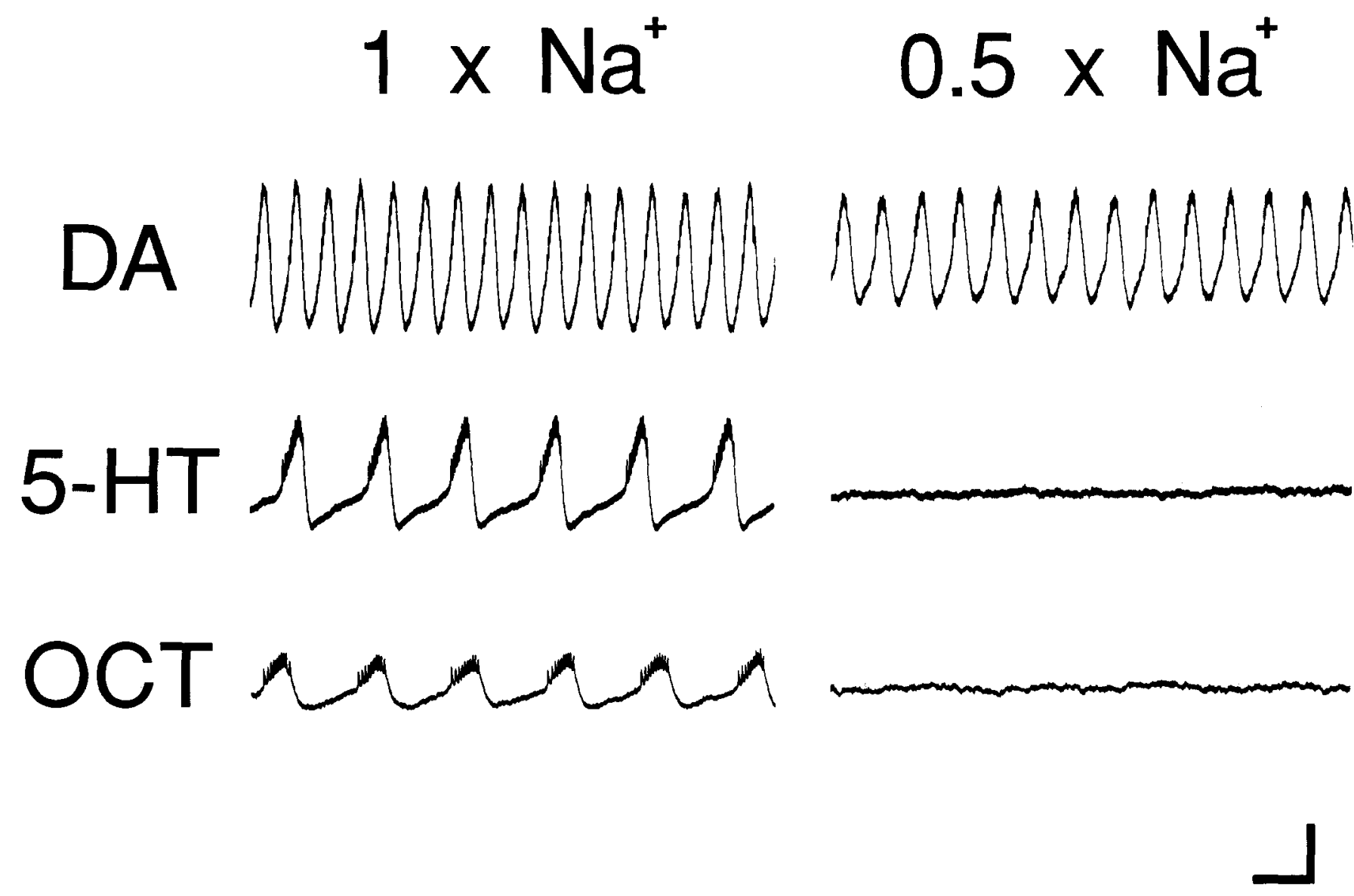

Figure 4. Effect of reduction in extracellular $\mathrm{Na}^{+}$on amine-induced bursting. All traces from a single experiment. The synaptically isolated cell had a flat resting potential of $-67 \mathrm{mV}$. Addition of $10^{-4} \mathrm{M} \mathrm{DA}, 10^{-5} \mathrm{M} 5-\mathrm{HT}$, or $10^{4} \mathrm{M}$ OCT induced rhythmic bursting $\left(I \times \mathrm{Na}^{+}\right)$. In the continued presence of the amine, the superfusing saline was switched to $0.5 \times \mathrm{Na}^{+}$saline (sodium replaced with Tris). Traces shown in $0.5 \times N a^{+}$column were made 5-7 min after change in saline. Voltage marker, $5 \mathrm{mV}$; time marker, $1 \mathrm{sec}$.

surface of the ganglion to burst-generating sites buried in the neuropil. Upon the elimination of bursting, the cell remained at a level somewhat depolarized from the original resting potential. Rhythmic oscillations could not be restored by current injection to hyperpolarize or depolarize the cell. This depolarization reversed upon removal of the amine.

In other experiments, TTX was added furst to abolish action potentials. Under these conditions, the $A B$ had a flat resting potential and BPPs and action potentials could not be induced by current injection. The addition of DA in the continued presence of TTX generated smooth BPPs with no action potentials, and this TTX-insensitive bursting behavior was stable for long periods. Addition of 5-HT or OCT to a TTX-treated preparation induced a small depolarization of 2-3 $\mathrm{mV}$, but no bursting behavior was obtained (not shown). In neurons with weak baseline bursting behavior in the absence of amines, TTX did not always abolish BPPs; these TTX-insensitive BPPs could be enhanced by $5-\mathrm{HT}$ or OCT.

Experiments with reduced extracellular sodium provided a second demonstration of the important role of $\mathrm{Na}^{+}$currents in 5-HT- and OCT-induced BPPs (Figs. 4, 5). When the extracellular $\mathrm{Na}^{+}$was reduced to $50 \%$ by replacement with either Tris or sucrose, bursting induced by 5-HT or OCT was rapidly terminated. The time course of this effect (Fig. $5 \mathrm{~A}$ ) shows that the burst peak and, to a lesser extent, the trough of the BPP were progressively reduced in amplitude until the cell fell silent at a potential somewhat depolarized from the original resting potential. During the entry of low-sodium saline, the BPP frequency declined continuously until the cell stopped bursting altogether (Fig. 5B). This inhibition of bursting was rapidly reversed upon restoration of normal saline (Fig. 5).

In contrast, reduction of extracellular sodium by $50 \%$ did not eliminate DA-induced BPPs (Fig. 4). The amplitude of the burst was reduced, primarily because of an apparent reduction in the amplitude of the interburst hyperpolarization (Fig. 5A). The burst frequency was only slightly affected (Fig. $5 B$ ). DA-induced BPPs continued upon further reduction of extracellular $\mathrm{Na}^{+}$to $25 \%$ of normal (Fig. 5). However, BPP amplitude was markedly decreased (Fig. $5 A$ ), frequency was somewhat decreased (Fig. $5 B$ ), and the BPPs had no detectable action potentials.

These results support the conclusion that TTX-sensitive $\mathrm{Na}^{+}$ currents are essential for BPP induction by 5-HT and OCT. However, Na' entry through TTX-sensitive channels is not essential for DA-induced BPPs, though $\mathrm{Na}^{+}$entry through other, TTX-insensitive channels probably plays a role (Fig. 5).

\section{Role of calcium}

The role of calcium currents in amine-generated BPPs was investigated by similar ion-substitution and channel-blockade experiments. When the extracellular calcium was reduced to $25 \%$ or less by replacement with $\mathrm{Mg}^{2+}$, DA-induced bursting rapidly ceased (Figs. 6, 7). The time course of this effect (Figs. 7, 8A) 
A
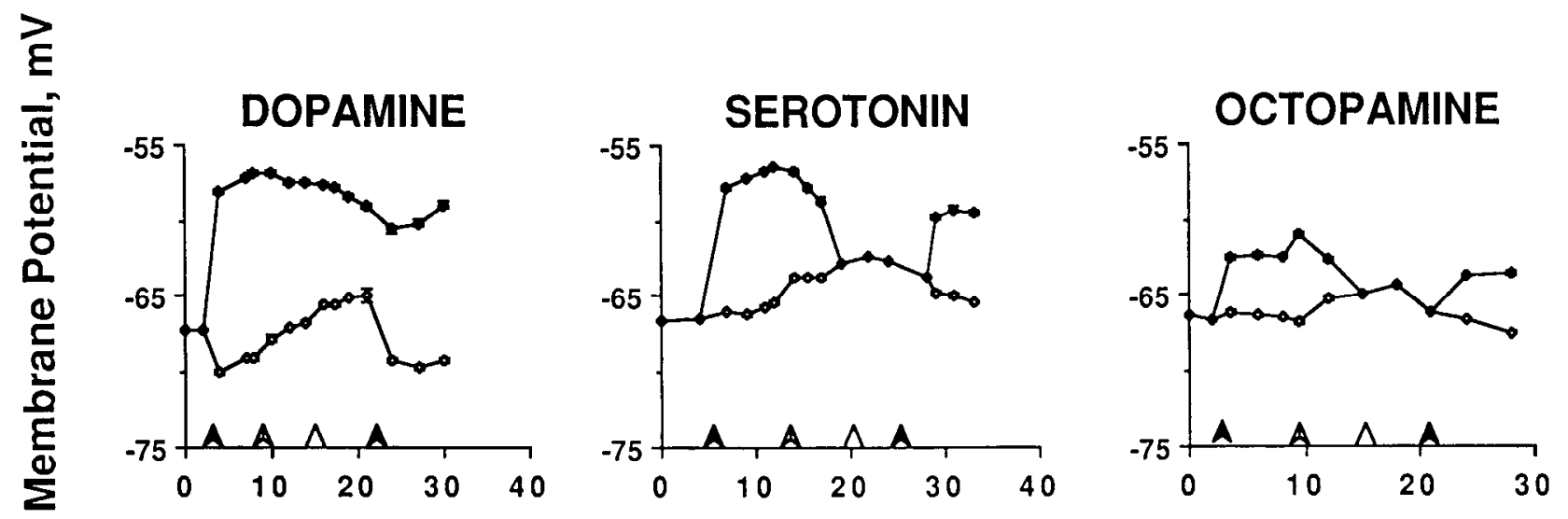

B
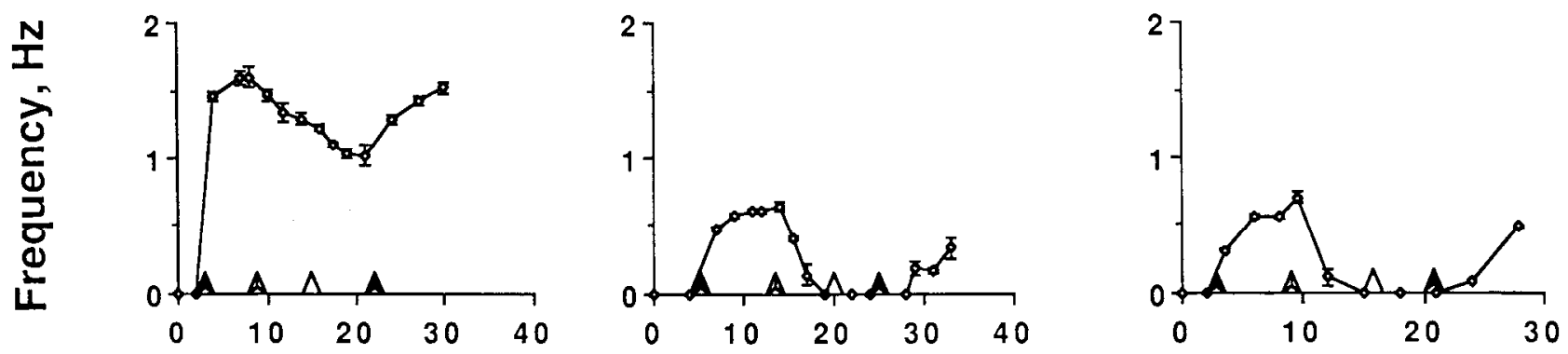

\section{Time, Min}

Figure 5. Time course of effects of reduction in extracellular sodium on amine-induced bursting. Data from the same experiment as in Figure 4. $A$, Effect on BPP amplitude. Filled symbols, burst peak value. Open symbols, interburst hyperpolarization value. $B$, Effect on BPP frequency. Instantaneous frequency was calculated as the inverse of the interburst interval. In both $A$ and $B$, symbols show the means of 10 determinations; $\mathrm{SD}$ is drawn where it exceeds the size of the symbol. Before amine addition, the cell was not bursting. The indicated amine was bath-applied in normal saline, starting at the first arrowhead from the left. At the indicated times, the saline was changed to $0.5 \times \mathrm{Na}^{+}$(second arrowhead), $0.25 \times \mathrm{Na}^{+}$(third arrowhead), and returned to normal $\left(1 \times \mathrm{Na}^{+}\right.$, fourth arrowhead), all in the continued presence of the amine.

shows that the major effect of reduced $\mathrm{Ca}^{2+}$ entry was a progressive depolarization of the interburst trough. The absolute value of the burst peak was not greatly affected until shortly before failure of the BPP, when it was sometimes reduced slightly (Fig. $7 A$ ). Thus, when the $\mathrm{AB}$ cell stopped oscillating, it remained depolarized at a level at or near the original burst peak value. The BPP frequency was relatively stable until the moment when bursting ceased (Fig. 7B). Bursting could not be restored by current injection to hyperpolarize the cell. This inhibition of bursting was rapidly reversible upon reintroduction of normal $\mathrm{Ca}^{2+}$ to the saline.

In contrast, reduction of extracellular $\mathrm{Ca}^{2+}$ to $25 \%$ of normal did not eliminate 5-HT- or OCT-induced BPPs (Figs. 6-8). The BPP amplitude was reduced, again primarily because of a depolarization of the burst trough (Figs. 6, 7A). In addition, the rate of repolarization terminating the BPP was reduced in lowcalcium saline (Figs. $6 ; 8 B, C$ ). In some experiments, a pronounced shoulder appeared on the falling phase of the BPP (Fig. $8 B$ ). The BPP frequency was progressively reduced in low- $\mathrm{Ca}^{2+}$ saline, in marked contrast to the relatively constant BPP frequency seen with DA up to the moment when bursting stopped altogether (Fig. 7B). 5-HT- and OCT-induced bursting was sta- ble for at least $25 \mathrm{~min}$ in $25 \% \mathrm{Ca}^{2+}$ saline. Further reduction of $\mathrm{Ca}^{2+}$ to $10 \%$ or lower had more marked effects on 5-HT- and OCT-induced BPPs (Figs. 6-8). The burst frequency was reduced (Fig. $7 B$ ), and both the depolarizing and repolarizing phases of the BPP were very slow (Fig. 6). In some experiments, slow but stable bursting continued in $10 \% \mathrm{Ca}^{2+}$ (Fig. 6), while in other experiments, bursting ceased and the cell remained at a very depolarized level, fired tonically at high frequencies, and occasionally fell silent (Fig. 8).

With all 3 amines, complete removal of $\mathrm{Ca}^{2+}$ from the saline (replaced by $\mathrm{Mg}^{2+}$, as well as addition of $\mathrm{Co}^{2+}(10 \mathrm{mM})$ or $\mathrm{Cd}^{2+}$ $(0.1-0.5 \mathrm{~mm})$ to normal saline, eliminated bursting. The cell remained silent at a depolarized level near the former peak of the BPP. These results show that, with all 3 amines, the repolarization that terminates the burst is sensitive to reduction in calcium entry. However, BPPs induced by DA are quantitatively more sensitive to reductions in extracellular calcium than are those induced by $5-\mathrm{HT}$ or OCT.

\section{Role of potassium}

Gola and Selverston (1981) found that extracellularly applied TEA enhanced the amplitude of the BPP peak in bursting PD 


\section{$1 \times \mathrm{Ca}^{++}$ \\ $0.25 \times \mathrm{Ca}^{++}$ \\ $0.1 \times \mathrm{Ca}^{++}$}

\section{DA Mocopocoupdoud

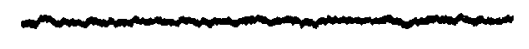

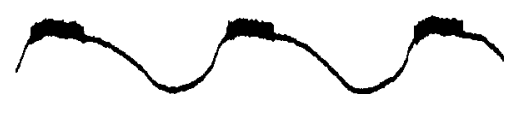
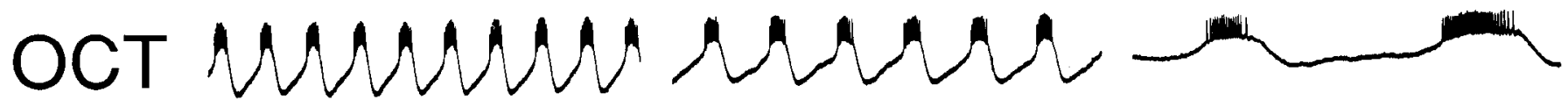

Figure 6. Effect of reduced extracellular calcium on amine-induced bursting. All traces from a single experiment. Stable rhythmic bursting was induced in normal saline by $10^{-4} \mathrm{M} \mathrm{DA}, 10^{-5} \mathrm{M} 5-\mathrm{HT}$, or $10^{-4} \mathrm{OCT}\left(1 \times \mathrm{Ca}^{2+}\right)$. The saline was then changed to $0.25 \times \mathrm{Ca}^{2+}(\mathrm{replacement}$ with $\mathrm{Mg}^{2+}$ ); traces are from $7 \mathrm{~min}$ after the saline change. The saline was then switched to $0.1 \times \mathrm{Ca}^{2+}$; again, traces are taken from about $7-8$ min after the saline switch. Upon return to normal saline, bursts returned to control levels seen in $1 \times \mathrm{Ca}^{2+}$. Voltage marker, $10 \mathrm{mV}$; time marker, 1 sec.

and AB cells. They suggested that BPPs are limited in amplitude by a potassium conductance that is active during the BPP peak. The different amplitudes of BPPs induced by different amines might reflect, in part, differences in the expression of this conductance. To test this hypothesis, we compared the BPP amplitude induced by each amine before and during the addition of $5 \mathrm{~mm}$ TEA to the bath (Figs. 9, 10). For all 3 amines, TEA addition increased the BPP amplitude, owing to increases in both the BPP peak and the interburst trough (Fig. 9). Note that, during TEA addition, the trough of the OCT-induced BPP was hyperpolarized below the pre-amine resting potential (indicated by the lines in Fig. 9). This was in marked contrast to the OCTinduced BPP in normal saline, which was entirely depolarized from the pre-amine resting potential. The greatest increase in BPP amplitude was with OCT. In 4 experiments, the OCTinduced BPP amplitude increased by $269 \pm 93 \%$, while the DAinduced BPP amplitude increased by $112 \pm 29 \%$ and the 5-HTinduced BPP amplitade increased by $147 \pm 43 \%$. This was a significant increase comparcd to the other amines $(p<0.05$; Student's $t$ test). However, even during TEA addition, the OCTinduced BPP amplitude remained somewhat smaller than the 5-HT- or DA-induced BPPs (Fig. 10). In 4 experiments, with TEA the OCT-induced BPP was $83 \pm 9 \%$, and the 5 -HT-induced BPP $94 \pm 10 \%$ of the DA-induced BPP. In addition, the BPP shapes and frequencies in TEA are different (Fig. 9). These results support the hypothesis that differences in a TEA-sensitive potassium conductance during the BPP overshoot account for part of the difference in BPP amplitudes that are induced by the 3 amines; however, other differences must also exist, as described above.

Changes in the extracellular potassium concentration also caused reproducible changes in burst amplitude and frequency, and these differed among the 3 amines (Fig. 11). In 3 experiments, the $\mathrm{AB}$ continued to show regular DA-induced BPPs at potassium concentrations ranging from $6.4 \mathrm{mM}(50 \%$ of normal) to $22.4 \mathrm{~mm}$ ( $175 \%$ of normal). The overall membrane potential depolarized as extracellular potassium was increased, and was accompanied by increased burst frequency (Fig. $11 B$ ). However, the peak and trough values of the BPP showed different dependencies on extracellular potassium, reflecting the different conductances dominating each phase of the burst (Fig. 11B). The dashed lines in Figure $11 B$ show the slope of the Nernst relation for potassium at $16^{\circ} \mathrm{C}(57 \mathrm{mV}$ potential change per decade, or 10-fold change, in extracellular potassium concentration). For potassium concentrations above $10 \mathrm{~mm}$, the DA-activated BPP trough values varied strongly with extracellular potassium, with a slope of $48 \mathrm{mV} /$ decade change in extracellular potassium. This suggests that potassium currents dominate during the undershoot. The overshoot value also changed with extracellular potassium, as was expected from the TEA results described above. However, it deviated markedly from the Nernst relation for potassium, with a slope of $30 \mathrm{mV} /$ decade.

Similar results were seen with 5-HT. Again, the overall membrane potential depolarized and the burst frequency increased with increased extracellular potassium. As with DA, the amplitude of the 5-HT-induced BPP trough varied strongly with potassium concentrations above $10 \mathrm{~mm}(43 \mathrm{mV} /$ decade change in extracellular potassium), while the values for the BPP peak deviated from an ideal potassium relation $(20 \mathrm{mV} /$ decade; Fig. $11 B$ ).

Somewhat different results were seen with OCT (Fig. 11). Upon a $50 \%$ reduction in potassium, the cell hyperpolarized and bursts almost ceased; the membrane potential had very small oscillations, with only one or 2 action potentials per burst. With increased potassium, the cell depolarized and OCT-induced bursts increased in frequency; bursting was rapid but weak in $1.75 \times \mathrm{K}^{+}$(Fig. 11). Both the burst peak and trough values varied with potassium. However, the interburst trough values 
A
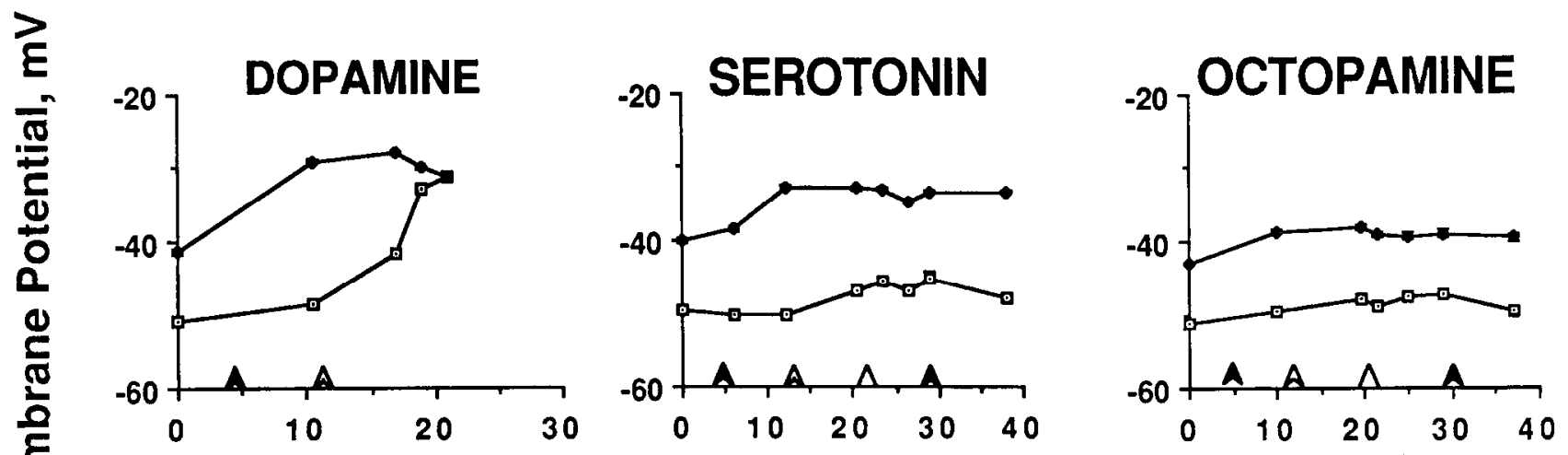

B
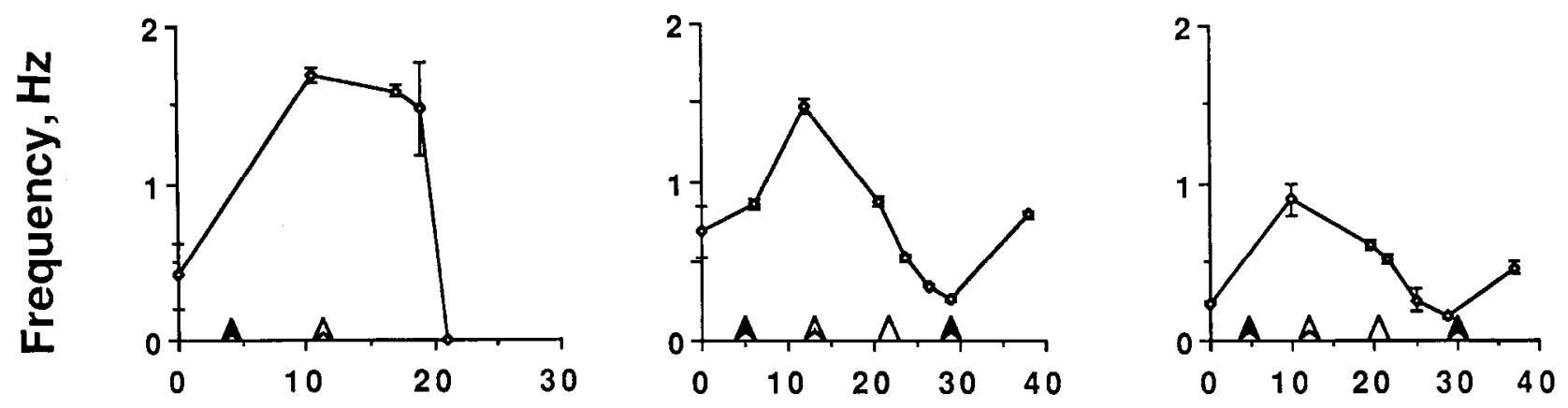

\section{Time, Min}

Figure 7. Time course of effect of reduced extracellular calcium on amine-induced bursting. $A$, Effect on BPP amplitude. Filled symbols, burst peak value. Open symbols, interburst hyperpolarization. $B$, Effect on BPP frequency. In both $A$ and $B$, symbols show the means of 10 determinations; SDs are drawn where they exceed the size of the symbol. In this preparation, the isolated AB cell had weak and irregular bursting in the absence of amines. Amines were first applied in normal saline (first arrowhead from left) then sequentially changed to $0.25 \times \mathrm{Ca}^{2+}$ (second arrowhead), $0.1 \times \mathrm{Ca}^{2+}$ (third arrowhead), then returned to $1 \times \mathrm{Ca}^{2+}($ fourth arrowhead)

for OCT-induced bursts had a much weaker dependence on extracellular potassium than did DA or 5-HT, showing an estimated change of only $26 \mathrm{mV}$ for a 10 -fold change in $\mathrm{K}^{+}$above $10 \mathrm{~mm}$ (Fig. $11 B$ ). These data suggest that potassium currents do not dominate during the OCT-induced burst trough to the same extent that they do with DA or 5-HT, and that other currents contribute significantly during this phase. This is consistent with the fact that the interburst trough is depolarized from the pre-OCT resting potential in normal saline (see horizontal lines in Fig. 11A). The burst peak showed a weak dependence on extracellular potassium $(20 \mathrm{mV} /$ decade $)$.

\section{Discussion}

Dopamine, octopamine, and serotonin all induce endogenous bursting pacemaker potentials in a quiescent $\mathrm{AB}$ cell. However, the 3 amines do not initiate bursting by a single, common mechanism. In the absence of voltage-clamp data, we are unable to describe the conductance changes induced in the AB cell by each amine in any detail, but the qualitative data derived from the use of ion-substitution and pharmacological blockade procedures have demonstrated differences in the currents activated by the amines at every step of the BPP cycle. These do not arise from simple differences in the concentration dependences of the
3 amines, since our experiments were performed at maximal concentrations for each amine (Flamm and Harris-Warrick, 1986a).

\section{Mechanism of burst initiation}

To initiate a burst, a rhythmic bursting cell must possess a depolarizing "pacemaker potential" that carries it above threshold for the initiation of spike activity. In other preparations, this is thought to result from the activation of prolonged calcium and/or sodium conductances, sometimes in combination with decreases in potassium currents (Gola and Selverston, 1981; Pinsker and Ayers, 1983; Tazaki and Cooke, 1983; Benson and Cooke, 1984; Adams and Levitan, 1985; Kramer and Zucker, $1985 \mathrm{a}, \mathrm{b})$. When the AB cell is activated by $5-\mathrm{HT}$ or OCT, the depolarization preceding a burst is critically dependent on sodium current flowing through TTX-sensitive channels. In the presence of $10^{-7} \mathrm{M}$ TTX, bursting induced by 5-HT and OCT is rapidly terminated (Fig. 2). If TTX is added before the amine, both 5-HT and OCT induce a small depolarization of $2-3 \mathrm{mV}$, showing that the amines can continue to elicit a net inward change in current in the presence of TTX. However, no bursting results, and bursting cannot be induced by current injection.

One possible explanation of these results is that the 5-HT- or 

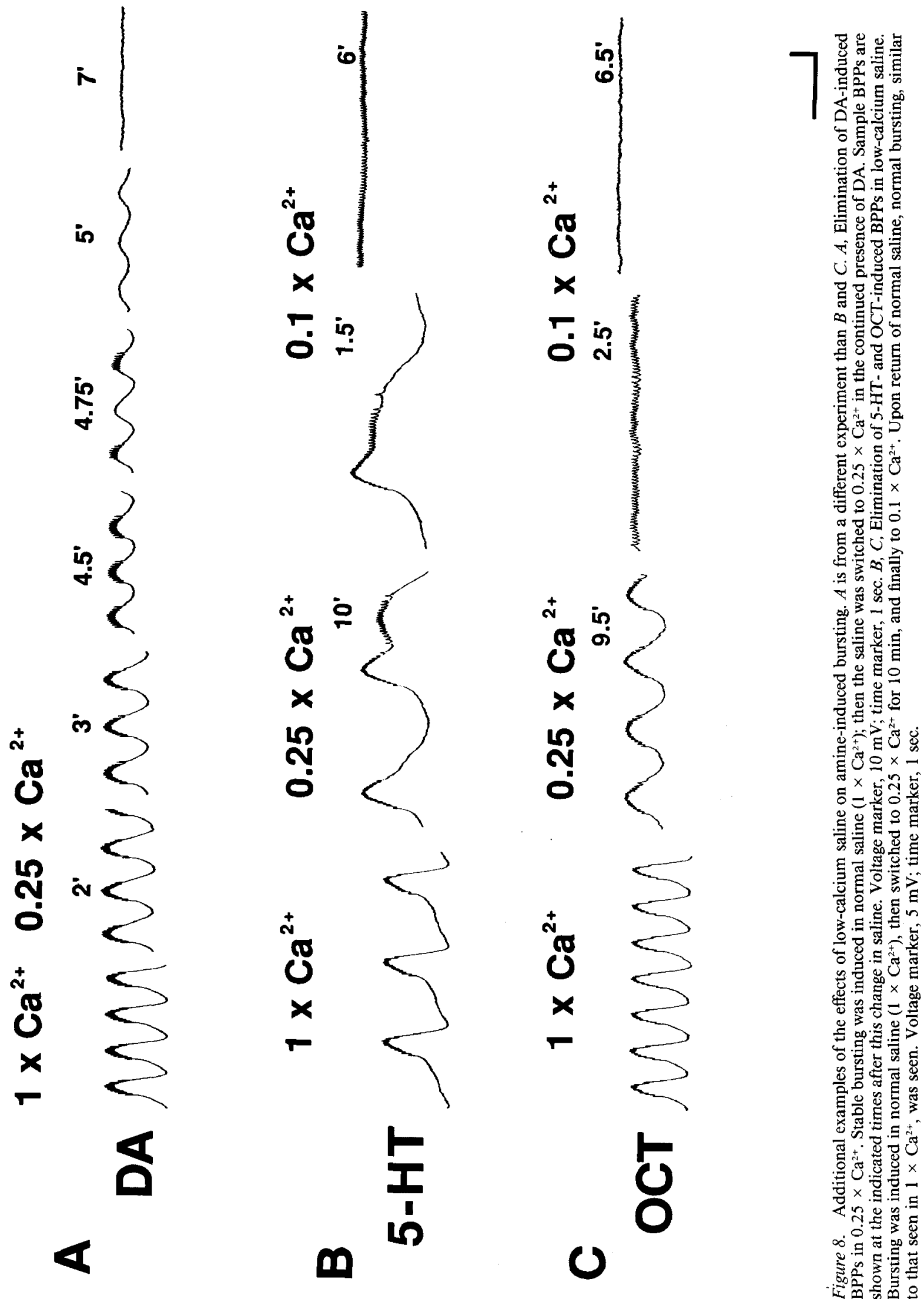


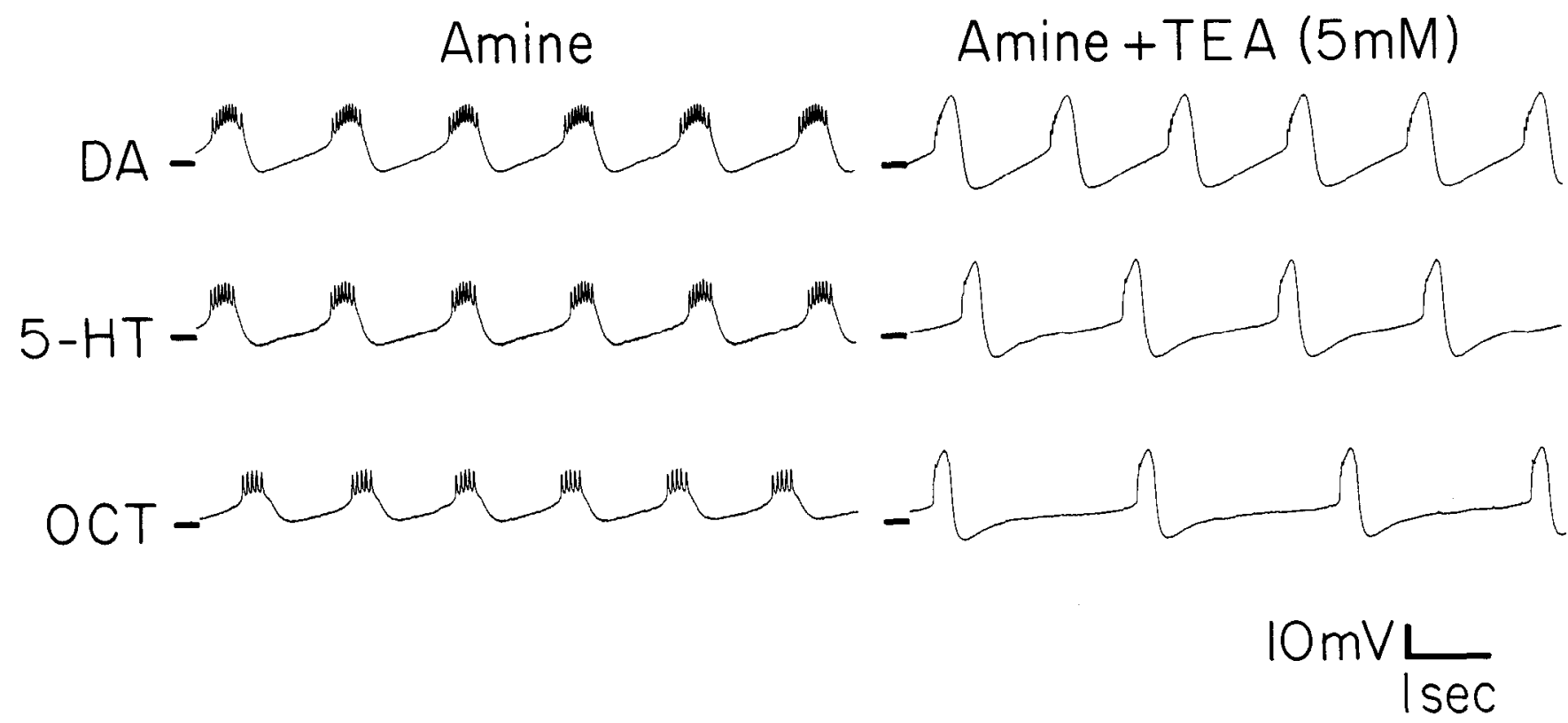

Figure 9. Effects of TEA on amine-induced bursting. Sample records all taken from a single experiment. The cell had a flat resting potential before amine addition. Bursting was induced in normal saline by each amine. When stable bursting was achieved (Amine), 5 mM TEA was added in the continued presence of the amine. Records (Amine $+T E A$ ) were taken 7-8 min after entry of TEA to the bath. Voltage marker, $10 \mathrm{mV}$; time marker, 1 sec.

OCT-induced bursts are triggered and maintained, in part, by the passive retrograde spread of axonal action potentials into the neuropil. This mechanism has been proposed for cell R15 in Aplysia (Adams and Benson, 1985; Adams and Levitan, 1985). However, we do not believe that this explanation is correct for 5-HT- or OCT-initiated bursting in the AB cell. During the entry of TTX into the bath, failure of action potentials occurs from $15 \mathrm{sec}$ to several minutes before failure of the bursting mechanism (Fig. 3). This shows that the eventual failure of BPPs does not result from action potential failure per se, but from reduced sodium entry through TTX-sensitive channels. This conclusion is further supported by experiments in which bursting induced by 5 -HT or OCT was eliminated upon the reduction of extracellular sodium to $50 \%$ of normal (Fig. 4). In several experiments, action potentials were also abolished with this treatment, but in 2 experiments, action potentials could still be evoked after bursting was abolished. In the experiment shown in Figure 4, for example, action potentials continued during DA-induced bursting in 50\% sodium, but bursting induced by 5-HT or OCT was abolished by this treatment.

In marked contrast to the results obtained with $5-\mathrm{HT}$ and OCT, TTX-sensitive sodium currents do not appear to be necessary for DA-induced BPPs (Raper, 1979; Anderson and Barker, 1981). The only effect of TTX during DA-induced bursting is to remove action potentials from the BPP; the amplitude, shape, and frequency of the BPP are only marginally affected (Fig. 2). DA can also activate rhythmic bursting in a preparation that has been preincubated with TTX. While these results show

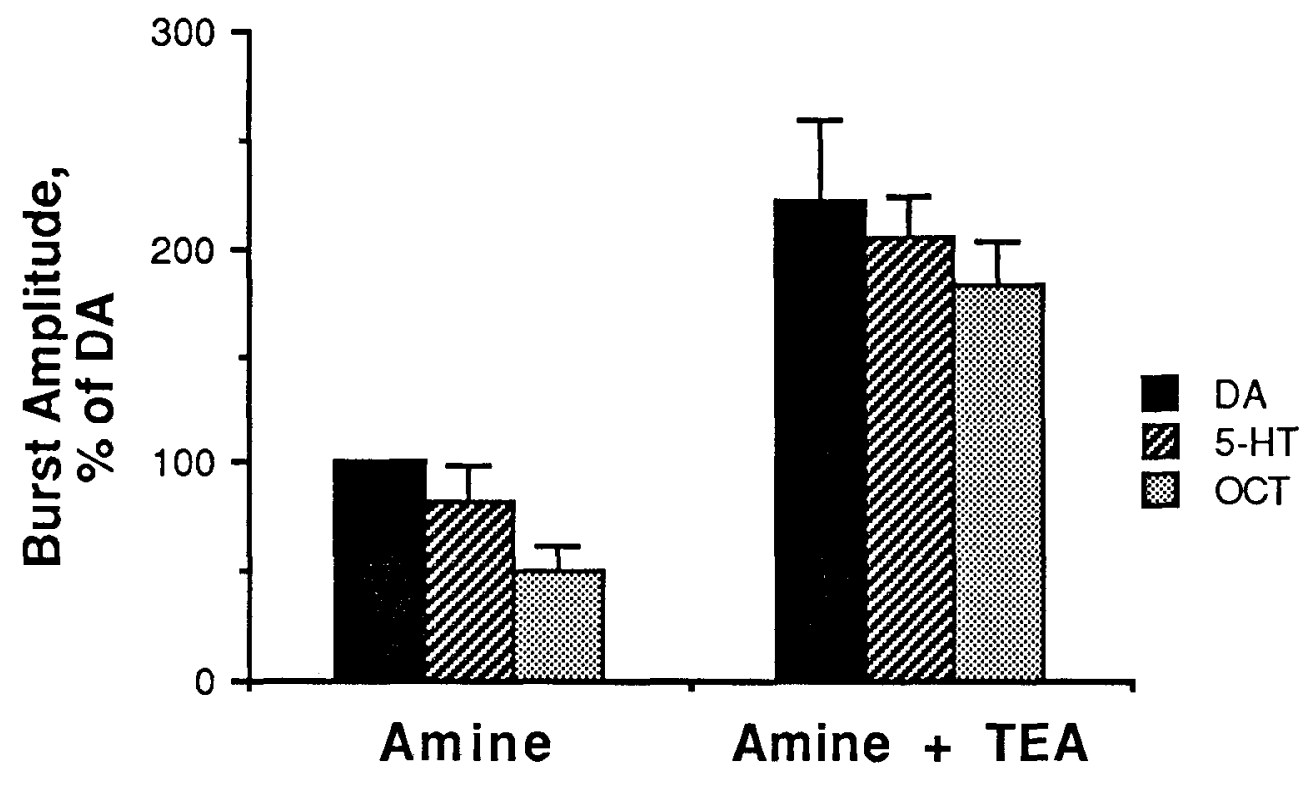

Figure 10. Change in amine-induced burst amplitude with TEA. Burst amplitude was measured from the interburst hyperpolarization to the burst peak at the base of the most depolarized action potential in the burst. In each experiment, values were normalized to the amplitude of the DA-induced BPP in normal saline, which is representcd by $100 \%$ on the ordinate. Values are means and SDs from 4 experiments. 
A
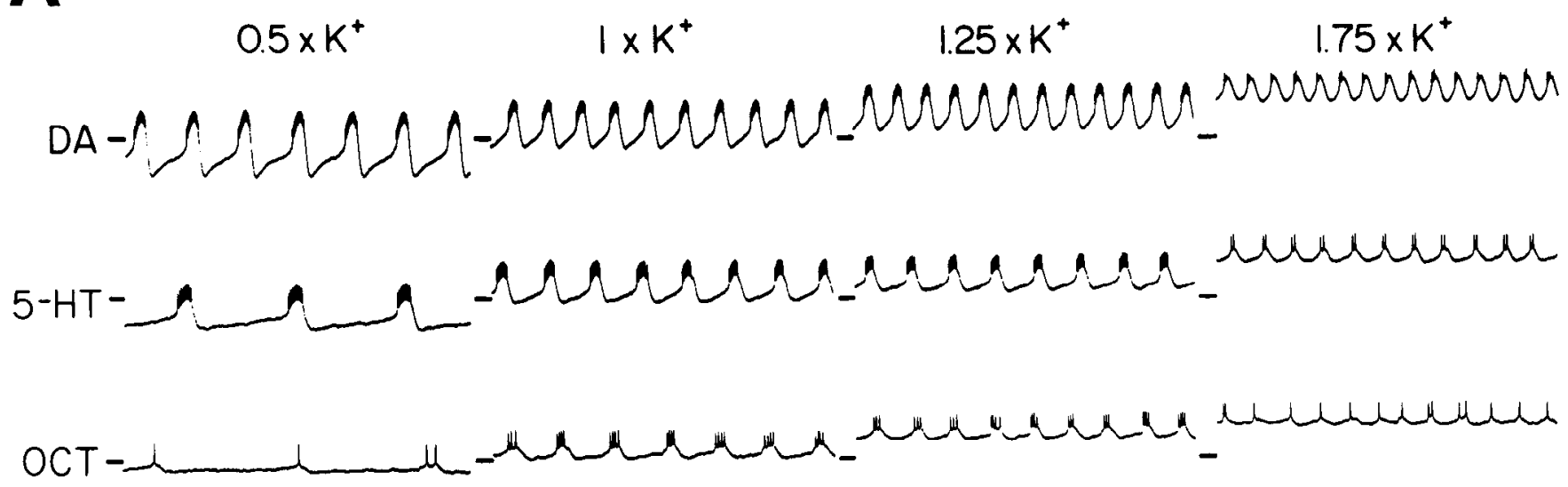

$5 \mathrm{mVL}$ I sec

B
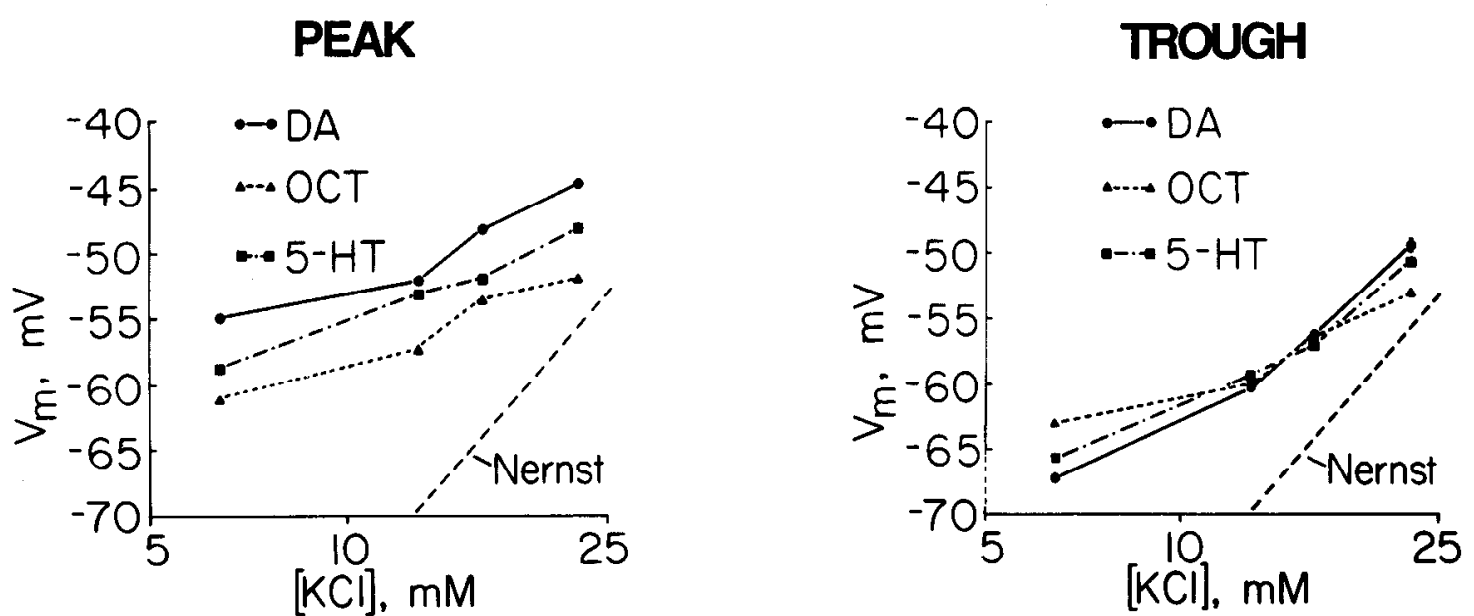

Figure 11. Effects of alterations in extracellular $\mathrm{K}^{+}$on amine-induced bursting. $A$, Sample recordings, all from a single experiment. This cell had a flat resting potential in normal saline, noted by the small horizontal lines between the traces. Stable bursting was induced by each amine in normal saline $\left(1 \times \mathrm{K}^{+}\right)$. In the continued presence of the amine, the saline was sequentially changed to $0.5 \times \mathrm{K}^{+}, 1.25 \times \mathrm{K}^{+}, 1.75 \times \mathrm{K}^{+}$, and returned to normal saline (not shown), which restored bursting similar to that seen initially in $1 \times \mathrm{K}^{+}$. Each record was taken $5-8$ min after a change in saline, when bursting had stabilized at a new level. Voltage marker, $5 \mathrm{mV}$; time marker, $1 \mathrm{sec}$. $B$, Dependence of the burst peak (Peak) and interburst hyperpolarization (Trough) on extracellular potassium concentration. Membrane potential $\left(\mathrm{V}_{m}\right)$ values are taken from records in $A$ and are means of 10 determinations; SDs are shown where they are larger than the symbol. To the right in each graph, the slope of a perfect Nernst relation for potassium at $15^{\circ} \mathrm{C}$ is shown (Nernst). The position of this line is arbitrary.

that I"IX-sensitive sodium currents are relatively unimportant in DA-induced BPPs, sodium flowing through other, TTX-inscnsitive channels probably does play a role. This can be seen in the low-sodium experiments, where the shape and frequency of DA-induced bursts were affected by a reduction in extracellular sodium (Figs. 4, 5).

\section{Currents active during the burst}

During the burst of action potentials, a prolonged depolarizing current must maintain the bursting cell above the action potential threshold. This inward current(s) must outweigh any outward currents that are simultaneously active. In most bursting cells, a prolonged calcium or calcium-activated inward conductance appears to underlie the burst (Gorman et al., 1980, 1982; Tazaki and Cooke, 1983; Adams and Levitan, 1985; Berlind, 1985; Kramer and Zucker, 1985a). In the AB cell, bursting induced by DA, 5-HT, or OCT ceases when calcium is removed, but the cell remains depolarized at or near the peak burst de- polarization (Figs. 6, 8). This suggests that the prolonged conductance that maintains the cell above threshold during a burst is not dependent on or primarily carried by calcium influx. Gola and Selverston (1981) came to a similar conclusion, suggesting that sodium influx plays a major role in burst generation in bursting PD cells.

The BPP peak amplitude is lower with OCT and has larger amplitude action potentials than BPPs induced by DA or 5-HT (Table 1). Like many other crustacean neurons, the AB cell body is electrically inexcitable. Action potentials are generated at a spike-initiation zone that is located at a distance from the soma, and they propagate passively over inexcitable membrane to our recording site in the soma (Selverston et al., 1976). Thus, the amplitude of the passively propagated action potential may be an indicator of the neuropil membrane resistance between the soma and the spike-initiation zone (Harris-Warrick and Kravitz, 1984). The larger-amplitude spikes seen during OCT superfusion than during DA or 5-HT superfusion would then re- 
sult from a higher membrane resistance during OCT. This would probably reflect a lower density of active inward channels, and is consistent with the lower amplitude of the burst. Alternatively, the location of the spike-initiation zone may shift with different amines; if it is closer to the soma during OCT, we would observe larger spikes in our recordings.

The differences in BPP amplitude may also reflect differences in outward currents. With all 3 amines, the burst peak can be dramatically increased by the addition of $5 \mathrm{~mm}$ TEA, but the most dramatic effect was on OCT-induced BPPs (Figs. 9, 10). Gola and Selverston (1981) suggested that TEA acts to block a potassium conductance that is active during the burst. We propose that during OCT-induced BPPs, the total conductance of this TEA-sensitive outward current is greater than during 5-HTor DA-induced bursting. This would hold the BPP below the threshold for activation of the larger, voltage-sensitive conductances that allow the greater overshoots during 5-HT and DA. Thus, the increased potassium conductance would prevent the voltage-sensitive conductances from being activated, reducing the apparent membrane resistance at the burst peak, as is implied from the larger-amplitude action potentials during OCTinduced bursting. The addition of TEA does not make OCTinduced bursts identical to DA- or 5-HT-induced bursts, however. The amplitude is always somewhat smaller, the bursts are narrower, and the burst frequency is always slower than bursts induced by DA (Гig. 9). This underscores the fact that multiple differences in ionic currents separate the effects of the 3 amines.

\section{Mechanism of burst termination}

For all 3 amines, burst termination and repolarization require calcium entry. As was mentioned above, when calcium current is reduced, either by replacement of most of the extracellular calcium by magnesium or by addition of cobalt or cadmium to the normal saline, amine-activated bursting ceases and the membrane potential remains depolarized near the peak of the BPP overshoot. However, there is a quantitative difference in calcium dependence for burst termination with different amines (Figs. 6, 7). DA-induced bursting ceases when extracellular $\mathrm{Ca}^{2+}$ is reduced to $25 \%$ of normal. 5-HT- and OCT-induced BPPs, although altered in shape and frequency, continue until $\mathrm{Ca}^{2+}$ levels are reduced to $10 \%$ or less. The effects of reduced calcium entry on burst frequency rcveal further differences between the amines. With $\mathrm{DA}$, as low $\mathrm{Ca}^{2+}$-high $\mathrm{Mg}^{2+}$ saline is superfused over the preparation, the cell bursts at a constant frequency, while the interburst trough becomes more and more depolarized until the cell finally stops bursting (Figs. 6-8). In contrast, with 5 -HT and OCT, the burst frequency is strongly dependent upon $\mathrm{Ca}^{2+}$ entry, decreasing with $\mathrm{Ca}^{2+}$ entry until bursting stops and the cell remains near the burst peak value (Fig. 8).

In the absence of voltage-clamp data, we cannot determine how calcium entry terminates the BPP. Two major possibilities can be suggested from other preparations. First, the BPP could be terminated by a calcium-activated potassium conductance (Gorman et al., 1980, 1982; Gola and Selverston, 1981; Brown and Griffith, 1983; Tazaki and Cooke, 1983). In the AB cell, this is suggested by the calcium dependence of burst termination, combined with the potassium dependence of the interburst hyperpolarization (see below). The greater calcium dependence of BPPs induced by DA than by the other amines could be explained by either a quantitative difference in the density of the conductance or by a selective activation of 2 calcium-activated potassium conductances with different calcium depen- dences. In mammalian neurons, 2 calcium-activated potassium channels with different conductances and calcium dependences have been reported (Romey and Lazdunski, 1984; Inoue et al., 1985; Miller et al., 1985; Abia et al., 1986).

Alternatively, calcium-dependent termination of bursting could result from $\mathrm{Ca}^{2+}$-dependent inactivation of a prolonged $\mathrm{Ca}^{2+}$ conductance. This occurs in Aplysia cells R 15 (Adams and Levitan, 1985) and L2-L6 (Kramer and Zucker, 1985b). In the $\mathrm{AB}$ cell, the quantitative difference in $\mathrm{Ca}^{2+}$ dependence between DA and the other amines could result from either different calcium channel densities with the 3 amines, or activation by the 3 amines of calcium channels with different $\mathrm{Ca}^{2+}$-inactivation dependencies.

\section{Currents active during the interburst hyperpolarization}

Following the termination of a burst, the $\mathrm{AB}$ cell hyperpolarizes during the interburst interval. The absolute level and ionic dependence of this hyperpolarization are different for OCT than for DA and 5-HT. With superfusion of DA and 5-HT, the interburst hyperpolarization appears to be dominated by potassium currents, although other currents prevent the cell from hyperpolarizing to $E_{\mathrm{K}}$ and make the potassium dependence of the undershoot somewhat less than that predicted by the Nernst equation (Fig. 11). With OCT, however, the interburst hyperpolarization is depolarized from the pre-amine resting potential, and the potassium dependence of the hyperpolarization is considerably less than Nernstian (Fig. 11), which suggests that other currents contribute significantly during this phase. Two possible explanations could account for this result. First, OCT could activate additional inward currents, not present with DA or $5-\mathrm{HT}$, during the interburst interval. Second, the potassium conductances that dominate the interburst interval during DA or 5-HT superfusion may not be activated to the same extent during OCT superfusion. For example, these conductances may be voltage-sensitive, and the low amplitude of the slow wave peak with OCT may not be adequate to activate them. Supporting this hypothesis is the finding that when the OCT-induced burst peak was increased by the addition of 5 mM TEA, a pronounced interburst hyperpolarization appeared (Fig. 9) that was similar in amplitude and potassium dependence to those activated by 5 -HT or DA during TEA (data not shown).

These experiments also show that the currents generating the interburst hyperpolarization are not sensitive to low concentrations of TEA. In fact, the interburst potential is significantly more hyperpolarized during TEA superfusion with all 3 amines, though this could occur as a secondary consequence of the elevated amplitude of the burst peak during TEA. The interburst hyperpolarization is probably caused by activation of one or more TEA-insensitive potassium conductances (Gola and Selverston, 1981). However, it is possible that potassium-independent mechanisms may be involved, as has been described for Aplysia cells R15 (Adams and Levitan, 1985) and L2-L6 (Kramer and Zucker, 1985b).

\section{Biological significance of multiple mechanisms for bursting}

Our experiments show that DA, OCT, and 5-HT induce bursting with different ionic dependences, resulting in differences in BPP frequency and amplitude. Are these differences of any biological relevance to the animal?

The $\mathrm{AB}$ neuron is a component of the CPG for the pyloric rhythm, a rhythmic pumping and filtering movement in the posterior region of the lobster stomach (Selverston et al., 1976). 
This circuit is composed of 14 neurons, extensively interconnected by electrotonic and chemical inhibitory synapses (Eisen and Marder, 1982; Miller and Selverston, 1982a, b). The AB neuron appears to be the most important cell in the circuit for setting the cycle frequency (Miller and Selverston, 1985). When the 3 amines are added to an isolated STG preparation, each generates rhythmic cycling in a quiescent pyloric CPG (Flamm and Harris-Warrick, 1986a). When we studied the effects of amines on synaptically isolated cells in the pyloric CPG, the $\mathrm{AB}$ was the only cell to show amine-induced endogenous bursting (Flamm and Harris-Warrick, 1986b). Thus, the very existence of a rhythmic pyloric motor pattern during amine addition is primarily due to the amines' ability to induce bursting in the AB cell. However, we should emphasize that we do not know the behavioral conditions that provoke the release of amines in the intact animal. In addition, other modulators can also initiate pyloric cycle activity (Hooper and Marder, 1984; Marder and Eisen, $1984 \mathrm{a}, \mathrm{b}$ ), so there are probably a number of ways to activate the pyloric $\mathrm{CPG}$ in vivo.

Since the AB cell is the most important cell in setting the cycle frequency in the intact pyloric $C P G$, the differences in amine-induced BPP cycle frequency in the isolated AB cell (Fig. 1, Table 1) could cause changes in the motor pattern cycle frequency in the synaptically intact ganglion, and this is, in fact, observed (Flamm and Harris-Warrick, 1986a). DA induced the highest BPP frequency in the isolated $A B$ cell (Table 1), and also the highest cycle frequency in the intact circuit (Flamm and Harris-Warrick, 1986a; R. E. Flamm, unpublished observations). Similarly, the lowest cycle frequency in the isolated $\mathrm{AB}$ cell and in the intact pyloric circuit was usually seen with OCT. Thus, the animal may set the pyloric rhythm frcquency in part by determining which mixture of neuromodulators are released in the STG at any moment. The amines also affect other cells in the pyloric CPG, however, and these effects must be taken into account in determining the overall effect of an amine on pyloric cycle frequency (Flamm and Harris-Warrick, 1986b).

In addition, differences in the amplitudes of the amine-activated $B P P s$ in the $A B$ cell could lead to subtle changes in the phase relations among the follower cells in the pyloric CPG (Eisen and Marder, 1984). In the STG, graded transmission is an important form of synaptic transmission between pyloric neurons (Graubard, 1978; Graubard et al., 1980, 1983). The large-amplitude BPPs induced by DA or 5-HT will cause more transmitter release onto follower cells than will the smalleramplitude BPPs elicited by OCT. This could have 2 opposing effects in the STG. On the one hand, the follower cells should be more strongly inhibited by an $\mathrm{AB}$ burst during $\mathrm{DA}$ or $5-\mathrm{HT}$ induction than during that of $\mathrm{OCT}$, and their recovery may be phase-delayed as a consequence. On the other hand, many pyloric cells show pronounced postinhibitory rebound; this could be enhanced in DA and 5-HT, as compared to OCT, leading to a phase advance. The relevance of this modulation of phase relations in the intact pyloric circuit is complicated by the fact that the follower cells are usually also directly affected by the amine (Flamm and Harris-Warrick, 1986b). Clearly the follower cells' phase relations are affected by their own state of excitability.

Other neuromodulators also affect the $\mathrm{AB}$ burst frequency (Hooper and Marder, 1984; Marder and Eisen, 1984b), and it is probable that a mixture of many modulators simultaneously affects the $\mathrm{AB}$ cell in the intact animal (Flamm and HarrisWarrick, 1986a, b; Harris-Warrick, 1987). By changing the quantitative composition of this mixture, burst frequency and phase relations can be altered in ways that are more flexible and subtle than those we have measured adding only one modulator at a time.

\section{Conclusion}

Even though we cannot quantitatively describe the ionic conductances underlying amine-induced bursting in the AB cell, it is clear that the ionic bases of bursting are different with different amines. We have demonstrated both quantitative and qualitative differences in the currents active during different phases of the burst. Several general conclusions may be drawn. First, a single cell can be induced to burst by more than one mechanism. There is no unique mechanism for sustaining rhythmic bursting activity in a single cell. Rather, a number of different ionic mechanisms can produce variants on the burst phenotype that may be useful to the animal. Second, it is very unlikely that any of the amines we have studied activate bursting by modulating a single ion conductance. Although bursting can be induced in the $\mathrm{AB}$ and in other stomatogastric neurons simply by blockade of potassium currents with higher concentrations of TEA (Nagy et al., 1985; Harris-Warrick and Johnson, 1987), this single mechanism cannot by itself explain the diversity of bursting mechanisms shown with DA, 5-HT, and OCT. We cannot envisage any single conductance change that could explain all of the differences between the amines described above. Each of the amines may activate one or more second messenger cascade mechanisms in the $\mathrm{AB}$, and these biochemical mechanisms could, in turn, activate multiple changes in the ionic conductances in the cell. We have recently shown that elevation of cAMP levels in a synaptically isolated AB cell induces bursting, but the details of the cAMP-induced bursts are somewhat different from those induced by any of the amines (R. E. Flamm, D. Fickbohm, and R. M. Harris-Warrick, unpublished observations). Third, the ability to generate bursts with different amplitudes and frequencies is biologically useful. As the most important cell for timing in the pyloric $C P G$, the $A B$, with these modifications of its burst mechanisms, can alter the overall motor pattern elicited in the stomach.

Bursting neurons have been described in vertebrates (Gahwiler and Dreifuss, 1979; Johnston et al., 1980; Andrew and Dudek, 1983, 1984; Grace and Bunney, 1984; Legendre et al., 1985; McCormick and Prince, 1986), and transmitter activation of conditional bursters has been reported in the lamprey spinal cord (Grillner and Wallen, 1985; Sigvardt et al., 1985; Wallen and Grillner, 1985) and the guinea pig nucleus tractus solitarius (Dekin et al., 1985). It will be intcresting to detcrminc whether mammalian conditional bursters also have multiple mechanisms for the induction of bursting.

\section{References}

Abia, A., C. D. Lobaton, A. Moreno, and J. Garcia-Sancho (1986) Leiurus quinquestriatus venom inhibits different kinds of $\mathrm{Ca}^{2+}$-dependent $\mathrm{K}^{+}$channels. Biochim. Biophys. Acta 856: 403-407.

Adams, W. B. (1985) Slow depolarizing and hyperpolarizing currents which mediate bursting in Aplysia neurone R15. J. Physiol. (Lond.) 360: 51-68.

Adams, W. B., and J. A. Benson (1985) The generation and modulation of endogenous rhythmicity in the Aplysia bursting pacemaker neurone R15. Prog. Biophys. Mol. Biol. 46: 1-49.

Adams, W. B., and I. B. Levitan (1985) Voltage and ion dependences of the slow currents which mediate bursting in Aplysia neurone R15. J. Physiol. (Lond.) 360: 69-93.

Anderson, W. W., and D. L. Barker (1981) Synaptic mechanisms that 
generate network oscillations in the absence of discrete postsynaptic potentials. J. Exp. Zool. 216: 187-191.

Andrew, R. D., and F. E. Dudek (1983) Burst discharge in mammalian neuroendocrine cells involves an intrinsic regenerative mechanism. Science 221: 1050-1052.

Andrew, R. D., and F. E. Dudek (1984) Analysis of intracellularly recorded phasic bursting by mammalian neuroendocrine cells. J. Neurophysiol. (Lond.) 51: 552-566.

Barker, J. L., and T. G. Smith (1976) Peptide regulation of neuronal membrane properties. Brain Res. 103: 167-169.

Beltz, B., J. S. Eisen, R. Flamm, R. Harris-Warrick, S. Hooper, and E. Marder (1984) Serotonergic innervation and modulation of the stomatogastric ganglion of three decapod crustaceans (Homarus americanus, Cancer irroratus, and Panulirus interruptus). J. Exp. Biol. 109: 35-54.

Benson, J. A., and I. M. Cooke (1984) Driver potentials and the organization of rhythmic bursting in crustacean ganglia. Trends Neurosci. 7: 85-91

Berlind, A. (1985) Endogenous burst-organizing potentials in two classes of neurons in the lobster cardiac ganglion respond differently to alterations in divalent ion concentration. J. Comp. Physiol. 157: 845856.

Berridge, M. J., and P. E. Rapp (1979) A comparative survey of the function, mechanism and control of cellular oscillators. J. Exp. Biol. 81: 217-279.

Brown, D. A., and W. H. Griffith (1983) Calcium-activaled outward current in voltage-clamped hippocampal neurones of the guinea pig. J. Physiol. (Lond.) 337: 287-301.

Connor, J. A. (1985) Neural pacemakers and rhythmicity. Annu. Rev. Physiol. 47: 17-28.

Dekin, M. S., G. B. Richerson, and P. A. Getting (1985) Thyrotropinreleasing hormone induces rhythmic bursting in neurons of the nucleus tractus solitarius. Science 229: 67-69.

Eisen, J. S., and E. Marder (1982) Mechanisms underlying pattern generation in lobster stomatogastric ganglion as determined by selective inactivation of identified neurons. III. Synaptic connections of electrically coupled pyloric neurons. J. Neurophysiol. 48: 1392-1415.

Eisen, J. S., and E. Marder (1984) A mechanism for the production of phase shifts in a pattern generator. J. Neurophysiol. 51: 13741393.

Flamm, R. E., and R. M. Harris-Warrick (1986a) Aminergic modulation in the lobster stomatogastric ganglion. I. Effects on the motor pattern and activity of neurons within the pyloric circuit. J. Neurophysiol. 55: 847-865.

Flamm, R. E., and R. M. Harris-Warrick (1986b) Aminergic modulation in the lobster stomatogastric ganglion. II. Target neurons of dopamine, octopamine and serotonin within the pyloric circuit. J. Neurophysiol 55: 866-881.

Gahwiler, B. H., and J. J. Dreifuss (1979) Phasically firing neurons in long term cultures of the rat hypothalamic supraoptic area: Pacemaker and follower cells. Brain Res. 177: 95-103.

Getting, P. A. (1987) Comparative analysis of invertebrate central pattern generators. In Neural Control of Rhythmic Movements, A. H. Cohen, S. Rossignol, and S. Grilhner, eds., Wiley, New York (in press).

Gola, M., and A. Selverston (1981) Ionic requirements for bursting activity in lobster stomatogastric neurons. J. Comp. Physiol. 145: 191-207.

Gorman, A. L. F., A. Hermann, and M. V. Thomas (1980) The neuronal pacemaker cycle. In Molluscan Nerve Cells: From Biophysics to Behavior, J. Koester and J. H. Byrne, eds., pp. 169-180, Cold Spring Harbor Laboratory, Cold Spring Harbor, NY.

Gorman, A. L. F., A. Hermann, and M. V. Thomas (1982) Ionic requirements for membrane oscillations and their dependence on the calcium concentration in a molluscan pace-maker neurone. J. Physiol. (Lond.) 327: 185-217.

Grace, A. A., and B. S. Bunney (1984) The control of firing pattern in nigral dopamine neurons: Burst firing. J. Neurosci. 4: 2877-2890.

Graubard, K. (1978) Synaptic transmission without action potentials: Input-output properties of a non-spiking presynaptic neuron. J. Neurophysiol. 41: 1014-1025.

Graubard, K., J. A. Raper, and D. K. Hartline (1980) Graded synaptic transmission between spiking neurons. Proc. Natl. Acad Sci. USA 77: 3733-3735.

Graubard, K., J. A. Raper, and D. K. Hartline (1983) Graded synaptic transmission between identified spiking neurons. J. Neurophysiol. 50: 508-521.
Grillner, S., and P. Wallen (1985) The ionic mechanisms underlying $\mathrm{N}$-methyl-D-aspartate receptor-induced, tetrodotoxin-resistant membrane potential oscillations in lamprey neurons active during locomotion. Neurosci. Lett. 60: 289-294.

Harris-Warrick, R. M. (1987) Chemical modulation of central pattern generators. In Neural Control of Rhythmic Movements, A. H. Cohen, S. Rossignol, and S. Grillner, eds., Wiley, New York (in press).

Harris-Warrick, R. M., and B. R. Johnson (1987) Potassium channel blockade induces rhythmic activity in a conditional burster neuron. Brain Res. (in press).

Harris-Warrick, R. M., and E. A. Kravitz (1984) Cellular mechanisms for modulation of posture by octopamine and serotonin in the lobster. J. Neurosci. 4: 1976-1993.

Hartline, D. K., J. Y. Palacio, and D. V. Gassie (1985) Voltage clamp studies of isolated somata from identitied pattern generator neurons in the lobster stomatogastric ganglion. Neurosci. Abstr. 11: 1023.

Hooper, S. L., and E. Marder (1984) Modulation of a central pattern generator by two neuropeptides, proctolin and FMRFamide. Brain Res. 305: 186-191.

Inoue, R., K. Kitamura, and H. Kuriyama (1985) Two Ca-dependent $\mathrm{K}$-channels classified by the application of tetraethylammonium distributed to smooth muscle membranes of the rabbit portal vein. Pfluegers Arch. 405: 173-179.

Johnston, D., J. J. Hablitz, and W. A. Wilson (1980) Voltage clamp discloses slow inward current in hippocampal burst-firing neurones. Nature 286: 391-393.

Kramer, R. H., and R. S. Zucker (1985a) Calcium-dependent inward current in Aplysia bursting pace-maker neurones. J. Physiol. (Lond.) 362: $107-130$.

Kramer, R. H., and R. S. Zucker (1985b) Calcium-induced inactivation of calcium current causes the inter-burst hyperpolarization of Aplysia bursting neurones. J. Physiol. (Lond.) 362: 131-160.

Legendre, P., J. S. McKenzie, B. Dupouy, and J. D. Vincent (1985) Evidence for bursting pacemaker neurones in cultured spinal cord cells. Neuroscience 16: 753-767.

Marder, E., and J. S. Eisen (1984a) Transmitter identification of pyloric neurons: Electrically coupled neurons use different transmitters. J. Neurophysiol. 51: 1345-1361.

Marder, E., and J. S. Eisen (1984b) Electrically coupled pacemaker neurons respond differently to the same physiological inputs and neurotransmitters. J. Neurophysiol. 51: 1362-1373.

McCormick, D. A., and D. A. Prince (1986) Acetylcholine induces burst firing in thalamic reticular neurones by activating a potassium conductance. Nature 319: 402-405.

Miller, C., E. Moczydlowski, R. Latorre, and M. Phillips (1985) Charybdotoxin, a protein inhibitor of single $\mathrm{Ca}^{2+}$-activated $\mathrm{K}^{+}$channels from mammalian skeletal muscle. Nature 313: 316-318.

Miller, J. P., and A. I. Selverston (1979) Rapid killing of single neurons by irradiation of intracellularly injected dye. Science 206: 702-704.

Miller, J. P., and A. I. Selverston (1982a) Mechanisms underlying pattern generation in lobster stomatogastric ganglion as determined by selective inactivation of identified neurons. II. Oscillatory properties of identified neurons. J. Neurophysiol. 48: 1378-1391.

Miller, J. P., and A. I. Selverston (1982b) Mechanisms underlying pattern generation in lobster stomatogastric ganglion as determined by selective inactivation of identified neurons. IV. Network properties of pyloric system. J. Neurophysiol. 48: 1416-1432.

Miller, J. P., and A. I. Selverston (1985) Neural mechanisms for the production of the lobster pyloric motor pattern. In Model Neural Networks and Behavior, A. I. Selverston, ed., pp. 37-48, Plenum, New York.

Moulins, M., and F. Nagy (1985) Fxtrinsic inputs and flexibility in the motor output of the lobster pyloric neural network. In Model Neural Networks and Behavior, A. I. Selverston, ed., pp. 49-68, Plenum, New York.

Mulloney, B., and A. I. Selverston (1974) Organization of the stomatogastric ganglion of the spiny lobster. I. Neurons driving the lateral teeth. J. Cump. Physiul. 91: 1-32.

Nagy, F., J. A. Benson, and M. Moulins (1984) Cholinergic activation of burst generating oscillations mediated by opening of $\mathrm{Ca}^{2+}$ channels in lobster pyloric neurons. Neurosci. Abst. 10: 148.

Nagy, F., J. A. Benson, and M. Moulins (1985) Cholinergic inputs reduce a steady outward $\mathrm{K}^{+}$current allowing activation of a $\mathrm{Ca}^{2+}$ conductance which underlies the burst-generating oscillations in lobster pyloric neurons. Neurosci. Abstr. 11: 1022.

Pinsker, H. M., and J. Ayers (1983) Neuronal oscillators. In The 
Clinical Neurosciences. Vol. 5: Neurobiology, R. N. Rosenberg, ed., pp. 203-266, Churchill Livingstone, New York.

Raper, J. A. (1979) Nonimpulse-mediated synaptic transmission during the generation of a cyclic motor program. Science 205: 304-306.

Rapp, P. E. (1979) An atlas of cellular oscillators. J. Exp. Biol. 81: 281-306.

Romey, G., and M. Lazdunski (1984) The coexistence in rat muscle cells of two distinct classes of $\mathrm{Ca}^{2+}$-dependent $\mathrm{K}^{+}$channels with different pharmacological properties and different physiological functions. Biochem. Biophys. Res. Commun. 118: 669-674.

Selverston, A. I., D. F. Russell, and J. P. Miller (1976) The stomatogastric ncrvous system: Structure and function of a small neural network. Prog. Neurobiol. 7: 215-290.

Sigvardt, K. A., S. Grillner, P. Wallen, and P. A. M. van Dongen (1985) Activation of NMDA receptors elicits fictive locomotion and bistable membrane properties in the lamprey spinal cord. Brain Res. 336. 390-395.
Smith, T. G., Jr. (1980) Ionic conduclances in bursting pacemaker cells and their hormonal modulation. In Molluscan Nerve Cells: From Biophysics to Behavior, J. Koester and J. H. Byrne, eds., pp. 135-143, Cold Spring Harbor Laboratory, Cold Spring Harbor, NY.

Tazaki, K., and I. M. Cooke (1979) Ionic bases of slow depolarizing responses of cardiac ganglion neurons in the crab, Portunus sanguinolentus. J. Neurophysiol. 42: 1022-1048.

Tazaki, K., and I. M. Cooke (1983) Neuronal mechanisms underlying rhythmic bursts in crustacean cardiac ganglia. In Neural Origin of Rhythmic Movements (Symposium of the Society of Experimental Biology, Vol. 37), A. Roberts and B. L. Roberts, eds., pp. 129-157, Cambridge U. P., Cambridge, UK.

Wallen, P., and S. Grillner (1985) The effect of current passage on $N$-methyl-D-aspartate-induced, tetrodotoxin-resistant membrane potential oscillations in lamprey neurons active during locomotion. Neurosci. Lett. 56: 87-93. 